\title{
An update on the management of chronic hepatitis C: 2015 Consensus guidelines from the Canadian Association for the Study of the Liver
}

\author{
Robert P Myers MD MSc ${ }^{1 *}$, Hemant Shah MD MScCH HPTE ${ }^{2 *}$, Kelly W Burak MD MSc${ }^{1}$, \\ Curtis Cooper $\mathrm{MD}^{3}$, Jordan J Feld $\mathrm{MD} \mathrm{MPH}^{2 *}$
}

\begin{abstract}
RP Myers, H Shah, KW Burak, C Cooper, JJ Feld. An update on the management of chronic hepatitis C: 2015 Consensus guidelines from the Canadian Association for the Study of the Liver. Can J Gastroenterol Hepatol 2015;29(1):19-34.
\end{abstract}

Chronic hepatitis $\mathrm{C}$ remains a significant medical and economic burden in Canada, affecting nearly $1 \%$ of the population. Since the last Canadian consensus conference on the management of chronic hepatitis $\mathrm{C}$, major advances have occurred that warrant a review of recommended management approaches for these patients. Specifically, direct-acting antiviral agents with dramatically improved rates of virological clearance compared with standard therapy have been developed and interferon-free, all-oral antiviral regimens have been approved. In light of this new evidence, an update to the 2012 Canadian Association for the Study of the Liver consensus guidelines on the management of hepatitis $\mathrm{C}$ was produced. The present document reviews the epidemiology of hepatitis $C$ in Canada, preferred diagnostic testing approaches and recommendations for the treatment of chronically infected patients with the newly approved antiviral agents, including those who have previously failed peginterferon and ribavirin-based therapy. In addition, recommendations are made regarding approaches to reducing the burden of hepatitis $\mathrm{C}$ in Canada.

Key Words: Dasabuvir; Direct-acting antivirals; Guideline; Hepatitis C; Interferon; Ledipasvir; Ombitasvir; Paritaprevir; Peginterferon; Simeprevir; Sofosbuvir; Ribavirin; Therapy; Treatment

\section{Mise à jour sur la prise en charge de l'hépatite $\mathrm{C}$ chronique : les lignes directrices consensuelles 2015 de l'Association canadienne pour l'étude du foie}

L'hépatite $\mathrm{C}$ chronique demeure un fardeau médical et économique important au Canada, car il touche près de $1 \%$ de la population. Depuis la dernière conférence consensuelle canadienne sur la prise en charge de l'hépatite $\mathrm{C}$ chronique, on a réalisé des progrès marqués qui justifient une analyse des démarches de prise en charge recommandées. Notamment, on a mis au point des antiviraux à action directe au taux de clairance virologique bien supérieur à celui du traitement standard et on a homologué des antiviraux sans interféron par voie orale. À la lumière de ces nouvelles données probantes, l'Association canadienne pour l'étude du foie a mis à jour les lignes directrices consensuelles 2012 sur la prise en charge de l'hépatite C. Le présent document traite de l'épidémiologie de l'hépatite $\mathrm{C}$ au Canada, des démarches et des recommandations favorisées pour traiter les patients atteints d'une infection chronique à l'aide des nouveaux antiviraux homologués, y compris les patients qui n'avaient pas répondu à un traitement à l'interféron pégylé et à la ribavirine. Il contient également des recommandations sur les approches pour réduire le fardeau de l'hépatite $\mathrm{C}$ au Canada.

\begin{abstract}
The present guidelines were written to assist physicians and other 1 health care professionals in the management of patients with chronic hepatitis $\mathrm{C}$ virus (HCV) infection. They were drafted by Canadian HCV experts at the request of the Executive Committee of the Canadian Association of the Study of the Liver (CASL). The document was made available for review by CASL members and a revised draft based on this feedback was submitted to the Executive Committee of CASL for approval. The information contained within the present guidelines represents a synthesis of evidence from the published literature and scientific abstract presentations available at the time of writing with supplementation by the expert opinions of the authors. Any recommendations should be considered preferred approaches to care rather than strict standards. In some cases, off-label use of regimens are recommended based on the authors' opinions. To more fully characterize the quality of evidence supporting these recommendations, we have assigned a class (reflecting benefit versus risk) and level (assessing strength of certainty) of evidence as adapted from the American College of Cardiology and the American Heart Association Practice Guidelines $(1,2)$, and as used in similar practice guidelines of CASL (3) and the American Association for the Study of Liver Diseases (4) (Table 1). No

Since the last update of the CASL management guidelines for chronic hepatitis C (CHC) in 2012 (3), major advances have occurred including: the approval of novel direct-acting antiviral agents (DAAs) used with pegylated interferon (PEG-IFN) that have improved efficacy and tolerability compared with first-generation DAAs and/or standard PEG-IFN-based therapy (5-7); and the approval of all-oral, IFN-free, DAA combination therapies with markedly improved efficacy and tolerability and activity beyond just HCV genotype 1 (5,8-15). The current document was developed as an update to previous guidelines with a focus on the management of $\mathrm{HCV}$-infected patients rather than an exhaustive review of $\mathrm{CHC}$ or HCV screening. Future guidelines will include 'special populations' with $\mathrm{CHC}$, including people who use injection drugs (PWIDs), incarcerated individuals, patients with decompensated cirrhosis, those pre- or post-transplantation, and patients with HIV/HCV coinfection (for whom relevant guidelines have recently been published by the Canadian Institute of Health Research HIV Trials Network) (16). Due to the rapidity of advances in this field, recommendations in the present document will be updated regularly as new information emerges and novel agents are approved.
\end{abstract} funding was provided to the authors for this work.

\footnotetext{
*Authors who contributed equally to this work.

${ }^{1}$ Liver Unit, Division of Gastroenterology and Hepatology, University of Calgary, Calgary, Alberta; ${ }^{2}$ Toronto Western Hospital Liver Centre, University of Toronto, Toronto; ${ }^{3}$ Division of Infectious Diseases, University of Ottawa, Ottawa, Ontario

Correspondence: Dr Robert P Myers, Liver Unit, University of Calgary, 6D22, Teaching, Research and Wellness Building, 3280 Hospital Drive

Northwest, Calgary, Alberta T2N 4Z6. Telephone 403-592-5049, fax 403-592-5090, e-mail rpmyers@ucalgary.ca

Received for publication December 17, 2014. Accepted December 18, 2014
} 
TABLE 1

Grading system for recommendations

\begin{tabular}{|c|c|}
\hline Classification & Description \\
\hline \multicolumn{2}{|c|}{ Class of evidence } \\
\hline Class 1 & $\begin{array}{l}\text { Conditions for which there is evidence and/or general agreement that a given diagnostic evaluation, procedure or treatment is beneficial, } \\
\text { useful and effective }\end{array}$ \\
\hline Class 2 & $\begin{array}{l}\text { Conditions for which there is conflicting evidence and/or a divergence of opinion about the usefulness/efficacy of a diagnostic evaluation, } \\
\text { procedure or treatment }\end{array}$ \\
\hline Class 2a & Weight of evidence/opinion is in favour of usefulness/efficacy \\
\hline Class $2 b$ & Usefulness/efficacy is less well established by evidence/opinion \\
\hline Class 3 & $\begin{array}{l}\text { Conditions for which there is evidence and/or general agreement that a diagnostic evaluation, procedure/treatment is not useful/effective } \\
\text { and in some cases may be harmful }\end{array}$ \\
\hline \multicolumn{2}{|c|}{ Grade of evidence } \\
\hline Level A & Data derived from multiple randomized clinical trials or meta-analyses \\
\hline Level B & Data derived from a single randomized trial, or nonrandomized studies \\
\hline Level C & Only consensus opinions of experts, case studies or standard-of-care \\
\hline
\end{tabular}

\section{EPIDEMIOLOGY OF HEPATITIS C IN CANADA}

$\mathrm{CHC}$ remains a significant medical and economic burden in Canada (17-19). In the Canadian Health Measures Survey (20), Statistics Canada and the Public Health Agency of Canada reported an estimated anti-HCV prevalence of $0.5 \%$ (95\% CI $0.3 \%$ to $0.9 \%)$ or approximately 138,600 (95\% CI 55,800 to 221,300) anti-HCV-positive individuals in Canada. However, these figures are likely underestimates because the Canadian Health Measures Survey excluded several high-risk populations including incarcerated individuals, Aboriginals and PWIDs (20). In fact, a recent modelling study suggests that approximately 252,000 Canadians (uncertainty interval 178,000 to $315,000)$ were chronically infected in 2013 (18). The peak prevalence was estimated to have occurred in 2003 , with approximately 260,000 infected individuals. It has been estimated that approximately $60 \%$ of $\mathrm{HCV}$ cases in Canada are among current or former PWIDs, 20\% are among infected immigrants and $11 \%$ have received contaminated blood products (21). Of the nearly 8000 incident cases in Canada in 2007, approximately $80 \%$ likely occurred via sharing of injecting equipment, and most of the remainder among immigrants from endemic countries (21). There is wide variation in estimates of the number of HCV-infected individuals who remain undiagnosed. Modelling data from the Public Health Agency of Canada estimated that $79 \%$ of individuals were diagnosed in 2003 (21); however, the CMHS found that only $30 \%$ of anti-HCV-positive individuals were aware of their infection (20).

Genotype 1 infection is the most prevalent genotype in Canada, representing $65 \%$ of infected individuals (56\% genotype 1a, 33\% genotype $1 \mathrm{~b}$, and $10 \%$ with an unspecified subtype or mixed infection) (22). The genotype 1 subtype is of relevance for some of the new antiviral regimens due to differing efficacy between genotypes $1 \mathrm{a}$ and $1 \mathrm{~b}$. Genotypes 2 and 3 account for approximately 14\% and 20\% of infections in Canada, respectively, whereas genotypes 4, 5 and 6 are very rare $(<1 \%$ of all infections) (22).

Although the overall prevalence of $\mathrm{CHC}$ is declining, complications of $\mathrm{CHC}$ are increasing due to aging of the infected population and progression of liver fibrosis (17-19). Modelling data suggest that by 2035 , cases of decompensated cirrhosis, hepatocellular carcinoma (HCC) and liver-related mortality will increase by $80 \%, 205 \%$ and 160\%, respectively, compared with 2013 levels (Figure 1) (18). Similarly, annual direct costs associated with $\mathrm{CHC}$ (excluding the cost of antiviral therapies) are expected to rise from an estimated $\$ 161$ million in 2013 to $>\$ 258$ million at the peak in 2032 (18). Given the alarming estimates of future disease burden, more accurate information regarding the incidence and prevalence of $\mathrm{CHC}$ and its sequelae is required to inform health care planning and the allocation of resources. The identification of undiagnosed cases and the dissemination of effective antiviral therapies should be prioritized to reduce complications of this disease (23).

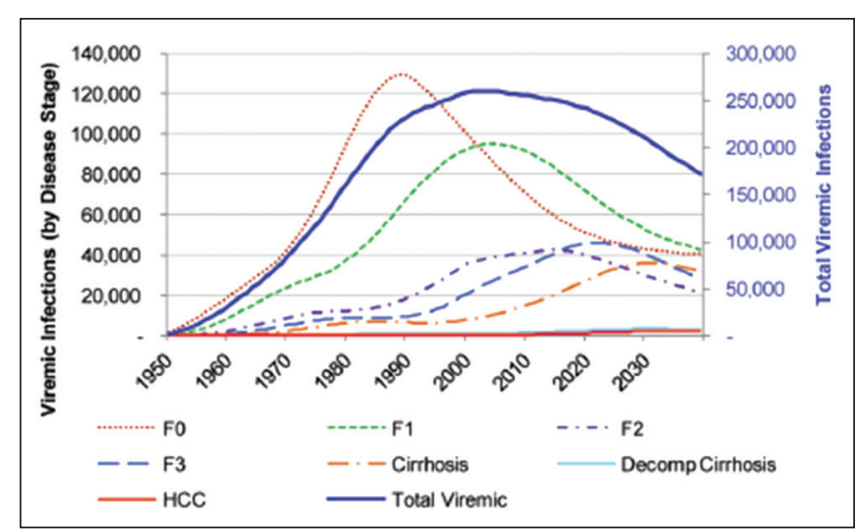

Figure 1) Modelled incidence of hepatitis C-related sequelae in Canada, 1950 to 2035. Estimates are not mutually exclusive. Reproduced with permission from Myers et al (18). Decomp Decompensated; HCC Hepatocellular carcinoma

Recommendations:

1. A large population-based seroprevalence survey should be conducted to accurately define the prevalence of hepatitis $\mathrm{C}$ in Canada. The design of the study should include populations with an increased risk of hepatitis C, particularly PWIDs, incarcerated individuals and immigrants from endemic countries (Class 2a, Level C).

2. To reduce the future burden of HCV-related morbidity and mortality in Canada, strategies for case identification, harm reduction and disease management - including but not limited to antiviral therapy - should be developed and implemented (Class 2a, Level C).

\section{ANTIVIRAL THERAPY}

The primary objective of anti-HCV therapy is complete eradication of the virus, termed a sustained virological response (SVR). SVR has traditionally been defined as undetectable serum HCV RNA at least 24 weeks following the end of treatment (SVR24) (24); however, recent data suggest that earlier assessment at 12 weeks after treatment (SVR12) is sufficient to define this outcome (25). Once achieved, an SVR is considered to be a long-term cure of the virus because late relapses are rare $(26,27)$. SVR is associated with long-term health benefits including improved quality of life $(28,29)$, extrahepatic manifestations of HCV (eg, cryoglobulinemic vasculitis) (30), liver histology (31,32), HCC incidence (33), liver-related morbidity and mortality (34-36), and all-cause mortality (33). 
The landscape of antiviral treatment for hepatitis $\mathrm{C}$ is changing rapidly. Until recently, the standard therapy was the combination of PEG-IFN and ribavirin (RBV), usually administered for 48 weeks in patients with genotype $1,4,5$ and 6 , and 24 weeks in those with genotypes 2 and 3 (3). Dual therapy achieves SVR rates of 40\% to $50 \%$ in patients with genotype 1 and approximately $80 \%$ in those with genotypes 2, 3, 5 and 6. Results for HCV genotype 4 are intermediate (3). In 2011, the first DAAs, boceprevir (BOC) and telaprevir (TVR), were approved for treatment of HCV genotype 1 in combination with PEGIFN and RBV. These nonstructural (NS) 3/4A protease inhibitors (PIs) substantially increase rates of SVR in both treatment-naive and previously treated patients compared with dual therapy (37-41). However, they are associated with significant toxicity, complex regimens involving response-guided therapy (RGT), drug-drug interactions (DDIs), and low response rates in patients with cirrhosis and previous treatment failures. In addition, BOC and TVR required coadministration with PEG-IFN and RBV for 24 to 48 weeks, markedly increased the cost of therapy, and are associated with the emergence of resistance-associated variants (RAVs) in the majority of patients who fail treatment (3). The subsequent approval of DAAs with improved efficacy and tolerability, shorter treatment durations, and the option of PEG-IFN- and RBV-free therapy, represents a major advance in the field.

The treatment of $\mathrm{CHC}$ is complex and resource intensive. Contributing factors include the high prevalence of psychiatric comorbidities in HCV-infected individuals (eg, depression and addictions), multiple modes of drug administration, side effects, and the requirement for careful on-treatment monitoring of symptoms and laboratory tests. The most successful model to deliver comprehensive $\mathrm{CHC}$ care is via a multidisciplinary approach including experienced physicians, nurses and allied health professionals (eg, psychologists, psychiatrists, addiction specialists and social workers). Currently in Canada, a relatively small number of physicians treat $\mathrm{CHC}$, leading in some cases to prolonged wait times for patients to be adequately evaluated and treated. These deficiencies in access to care are greater in rural and remote communities, despite a high HCV prevalence in many regions with limited health care capacity. Moreover, public funding for treatment nurses who have represented a vital component of the management team - is not universally available. To achieve a meaningful reduction in the future burden of $\mathrm{CHC}$, it will be vital to expand treatment capacity via additional training and funding of experienced personnel and enhanced access to publically funded antiviral therapies (42). With the advent of all-oral antiviral regimens that have few contraindications, minimal toxicity and short treatment courses, the number of patients that can be treated should increase dramatically. However, team-based management will still be necessary to achieve this goal.

\section{Recommendation:}

3. Increased resources are necessary to improve hepatitis $\mathrm{C}$ treatment capacity in Canada, including the training of expert treaters and public funding for treatment nurses (Class 2a, Level C).

\section{INDICATIONS AND CONTRAINDICATIONS TO ANTIVIRAL TREATMENT}

All patients with $\mathrm{CHC}$ should be considered candidates for antiviral treatment. The decision of if and when to initiate therapy should be based on the balance between the perceived benefits and risks of treatment and the wishes of the individual patient. Factors to consider include the probability of SVR and the likelihood of progression to advanced liver disease without viral eradication, the presence of extrahepatic manifestations of $\mathrm{CHC}$, the patient's anticipated tolerability of treatment and the life expectancy of the patient. The prospect of new therapies with expected benefits over currently available treatments should also be considered. In light of these issues, prompt initiation of treatment should be considered in certain patient subgroups, especially those with advanced liver fibrosis (F3 or F4 according to the METAVIR classification [bridging fibrosis or cirrhosis]) (43). These patients are at
TABLE 2

Contraindications for treatment with peginterferon and ribavirin

\begin{tabular}{ll}
\hline $\begin{array}{l}\text { Absolute contraindications } \\
\text { contraindications }\end{array}$ & Pregnancy \\
& Alcohol abuse \\
& Copatic decompensation \\
Relative contraindications & Solid organ transplantation (except liver) \\
& Major depression \\
& Major psychosis \\
& Autoimmune disease \\
& Injection drug use \\
& Renal failure (including dialysis) \\
Contraindications that are no & Normal alanine aminotransferase \\
longer contraindications & Stable methadone maintenance \\
& Neutropenia, anemia or thrombocytopenia \\
& Controlled seizure disorder \\
& Older than 65 years of age \\
& Alcohol use
\end{tabular}

Table reproduced with permission from (3)

the highest risk of HCV-related complications including liver failure and HCC. Treatment of patients with mild to moderate fibrosis (F1 or F2) should also be considered because progression to more advanced stages is associated with a reduced likelihood of SVR. Moreover, viral eradication in patients at risk of infecting others (eg, PWIDs who continue to share injecting equipment) may reduce the incidence of new infections (44). The curative nature of HCV therapy means that those who achieve SVR before developing cirrhosis do not require long-term follow-up. There are additional benefits to SVR beyond liver disease prevention, including improved quality of life $(28,29)$ and a reduction in all-cause mortality (33). Patients with extrahepatic manifestations of CHC including cryoglobulinemic vasculitis, porphyria cutanea tarda and glomerulonephritis should be considered for treatment regardless of their underlying liver disease severity because these conditions typically respond to viral eradication (30).

There are very few absolute contraindications to treatment with PEG-IFN-and RBV- based therapy. As postmarketing experience with these therapies has grown, many conditions previously regarded as absolute contraindications are now considered relative, and some may be present only temporarily (Table 2) (3). In most cases, treatment of these patients with PEG-IFN and RBV requires considerable expertise and, therefore, patients with relative contraindications should be treated in expert centres. Contraindications to the recently approved, all-oral regimens are distinctly uncommon.

\section{Recommendations: \\ 4. All patients with chronic HCV infection should be considered candidates for antiviral therapy (Class 1, Level A). \\ 5. Antiviral treatment should be strongly considered in patients with evidence of liver fibrosis (Class 1, Level A). \\ 6. Patients with extrahepatic manifestations of HCV should be considered for antiviral therapy (Class 1, Level A).}

\section{Routine assessment}

\section{PRETREATMENT ASSESSMENT}

The routine assessment of $\mathrm{HCV}$-infected patients should include risk factors for viral acquisition (eg, injection drug use, receipt of potentially contaminated blood products or tissues, and origin from a highprevalence region), signs and symptoms of advanced liver disease (eg, jaundice, ascites, encephalopathy, portal hypertension-related hemorrhage) or extrahepatic manifestations of $\mathrm{CHC}$, presence of cofactors that may accelerate disease progression (eg, alcohol use, obesity, 


\section{TABLE 3}

Routine testing of patients with chronic hepatitis C virus (HCV)*

\begin{tabular}{|c|c|c|}
\hline Category of Testing & Tests & Comments \\
\hline \multirow{2}{*}{$\begin{array}{l}\text { Confirmation and characterization of } \\
\text { chronic infection }\end{array}$} & HCV RNA & Confirms chronicity and baseline for treatment responses \\
\hline & HCV genotype and subtype & Directs choice of treatment regimen \\
\hline \multirow[t]{10}{*}{ Assessment of liver disease } & Complete blood count & $\begin{array}{l}\text { Thrombocytopenia may indicate cirrhosis and portal hypertension. } \\
\text { Platelets needed for APRI calculation }\end{array}$ \\
\hline & Alanine aminotransferase & Normal value does not preclude significant fibrosis \\
\hline & Asparatate aminotransferase & Asparatate aminotransferase needed for calculation of APRI \\
\hline & Gamma-glutamyl transferase & \\
\hline & Alkaline phosphatase & \\
\hline & Bilirubin & $\begin{array}{l}\text { Elevated bilirubin or INR, or hypoalbuminemia may indicate significant } \\
\text { liver dysfunction }\end{array}$ \\
\hline & INR (or prothrombin time) & \\
\hline & Albumin & \\
\hline & Creatinine & $\begin{array}{l}\text { Renal dysfunction increases ribavirin-related hemolytic anemia and may } \\
\text { impact drug pharmacodynamics }\end{array}$ \\
\hline & Abdominal ultrasound & $\begin{array}{l}\text { May suggest cirrhosis, in which case, serves as a baseline for } \\
\text { hepatocellular carcinoma surveillance }\end{array}$ \\
\hline \multirow[t]{4}{*}{ Viral coinfections } & Immunoglobulin G anti-HAV & If negative, vaccinate against hepatitis $A$ \\
\hline & HBsAg & Exclude hepatitis B coinfection \\
\hline & Hepatitis B surface antibody & If negative (and HBsAg-negative), vaccinate against hepatitis B \\
\hline & anti-HIV & Exclude HIV coinfection \\
\hline \multirow[t]{9}{*}{ Exclude other causes of liver disease ${ }^{\dagger}$} & Alpha-1-antitrypsin & Alpha-1-antitrypsin deficiency \\
\hline & Ceruloplasmin & Wilson disease. \\
\hline & Ferritin, serum iron, total iron-binding capacity & Iron overload \\
\hline & Antinuclear antibody & Autoimmune hepatitis \\
\hline & Smooth muscle antibody & \\
\hline & Antimitochrondrial antibody & Primary biliary cirrhosis \\
\hline & Immunoglobulin G & Often elevated in autoimmune hepatitis and cirrhosis of any cause \\
\hline & Immunoglobulin A & Often elevated in fatty liver and alcoholic liver disease \\
\hline & Immunoglobulin M & Often elevated in primary biliary cirrhosis \\
\hline \multirow[t]{4}{*}{ Contraindications to treatment } & Serum or urine $\beta$-human chorionic gonadotropin & Exclude pregnancy in women of reproductive age \\
\hline & Electrocardiogram & If $>50$ years of age or history of cardiac disease \\
\hline & Thyroid-stimulating hormone & Exclude thyroid disease, which may be exacerbated by interferon \\
\hline & Fundoscopy & $\begin{array}{l}\text { Exclude retinopathy in patients }>50 \text { years of age or with hypertension or } \\
\text { diabetes mellitus if interferon is to be prescribed }\end{array}$ \\
\hline
\end{tabular}

${ }^{*}$ Confirmed anti-HCV antibody positive; ${ }^{\dagger}$ Suggested tests only. Tailor testing to individual case. Anti-HAV Antibodies to hepatitis A virus; APRI Aspartate aminotransferase/platelet ratio index; HBsAg Hepatitis B surface antigen; INR International normalized ratio

coinfections) and potential contraindications to IFN-based therapy (Table 2), which would favour the use of an IFN-free regimen. Necessary laboratory testing includes virological tests to confirm and characterize HCV infection, liver biochemistry, abdominal ultrasound, an assessment of fibrosis stage and tests to rule out coinfections, direct appropriate vaccination and identify contraindications to treatment. In patients with abnormal liver biochemistry, serological tests to exclude coexisting liver diseases should be considered (Table 3).

Virological testing

Approximately one-quarter of patients infected with HCV will clear the virus spontaneously (45). Therefore, chronic HCV infection must be confirmed in all anti-HCV-positive individuals using a sensitive HCV RNA test. HCV RNA detection and quantification using realtime polymerase chain reaction assays is standard due to their sensitivity, specificity, accuracy and broad dynamic range. Results should be expressed in IU/mL and normalized to the WHO international standard. Quantitative assays with a lower limit of detection of approximately $10 \mathrm{IU} / \mathrm{mL}$ to $15 \mathrm{IU} / \mathrm{mL}$ are recommended. HCV RNA test results should be available within a timely fashion (within seven days) to facilitate management decisions. The rapid identification of failing treatment will reduce patient exposure to costly therapies and potential toxicity, and likely limit the development of RAVs.

The HCV genotype should be assessed in all patients because it has important implications for the decision to initiate treatment and the choice of regimen. With PEG-IFN and RBV therapy, knowledge of only the main genotype ( 1 to 6 ) was necessary. However, knowledge of the subtype is now critical, particularly for genotype 1 , because of the differing genetic barriers to resistance of HCV subtypes $1 \mathrm{a}$ and $1 \mathrm{~b}$ for many classes of DAAs $(46,47)$. For some DAAs, additional testing (eg, for the Q80K polymorphism [see below]) and/or alternative treatment based on subtype (eg, the use of RBV) may be required.

\section{Recommendations:}

7. HCV RNA, genotype, and subtype testing (ie, 1a versus $1 \mathrm{~b}$ ) are essential to the management of patients with chronic hepatitis C (Class 1, Level A).

8. HCV RNA testing should be performed using a sensitive quantitative assay (lower limit of detection of $\leq 10 \mathrm{IU} / \mathrm{mL}$ to $15 \mathrm{IU} / \mathrm{mL}$ ) with a broad dynamic range. Standardized results should be expressed in $\mathrm{IU} / \mathrm{mL}$ and be available within a maximum of seven days to facilitate management decisions (Class 1, Level A).

Assessment of liver disease severity

Assessment of the severity of hepatic fibrosis is vital for determining the prognosis of $\mathrm{HCV}$-infected patients and the necessity of antiviral treatment. Identification of patients with cirrhosis is particularly important due to their increased risk of hepatic complications, reduced 
likelihood of treatment response, and their requirement for surveillance for HCC and esophageal varices. Although the diagnosis of cirrhosis is obvious in some cases based on routine tests (eg, a nodular shrunken liver, splenomegaly or portal hypertensive collaterals on ultrasound), traditionally, liver biopsy has been the reference method for staging fibrosis, determining the severity of other histological lesions (eg, necroinflammation, steatosis) and ruling out coexistent liver diseases (eg, iron overload). Various validated scoring systems have demonstrated sufficient reproducibility and interobserver variability to justify clinical use (eg, METAVIR, Scheuer, Ishak, and Knodell's Hepatic Activity Index) (48). However, liver biopsy has several limitations, including invasiveness and the potential for serious complications including hemorrhage (approximately one in 1000) and death (approximately one in 10,000) $(49,50)$, sampling error and variability in pathological interpretation, high cost, limited availability in many centres, and the difficulty of repeating biopsies to monitor temporal changes in fibrosis. In light of these limitations, numerous noninvasive alternatives to biopsy have been developed (51) including serum markers (eg, the aspartate aminotransferase/platelet ratio index [52]), FibroTest (FibroSure, LabCorp, USA) (53), transient elastography (TE; FibroScan, Echosens, France) (54-57) and other imagingbased tools $(58,59)$.

Although not universally available, a wealth of literature has confirmed that these noninvasive tools can be used instead of liver biopsy to stage HCV-related fibrosis at acceptable levels of accuracy and reproducibility. In a recent survey of Canadian specialists who manage patients with chronic liver disease (60), TE was the primary mode of fibrosis assessment in $\mathrm{HCV}$-infected individuals in $53 \%$ of respondents, followed by liver biopsy in $37 \%$. Nearly one-half of respondents estimated that these noninvasive alternatives have reduced their use of liver biopsy by over $50 \%$. In general, these tests are highly accurate for diagnosing cirrhosis and have acceptable, but lower, performance for moderate to severe fibrosis (F2 or greater). The identification of mild fibrosis (F1) and the differentiation between individual stages is poor; however, these limitations also apply to liver biopsy. Emerging data have also demonstrated a correlation between these tests and HCVrelated clinical outcomes (61-63), their cost-effectiveness compared with biopsy (64) and responsiveness to viral eradication $(65,66)$. Future studies are necessary to determine the minimal clinically important changes in these markers to facilitate serial monitoring of fibrosis.

\section{Recommendations:}

9. Liver fibrosis assessment is vital to the management of patients with CHC (Class 1, Level A).

10. Acceptable methods of fibrosis assessment include liver biopsy, TE (FibroScan) and serum biomarker panels (eg, FibroTest), either alone or in combination. All jurisdictions should provide access to at least one accurate, noninvasive method to assess fibrosis (Class 1, Level A).

11. Alternatively, cirrhosis can be confidently diagnosed in some patients with clear clinical or radiographic evidence (Class 2a Level C).

\section{Utility of interleukin $28 \mathrm{~B}$ testing}

Genome-wide association studies have identified single nucleotide polymorphisms (SNPs) near the interleukin 28B (IL28B) gene on chromosome 19 that are strongly associated with both spontaneous and treatment-induced HCV clearance (67-70). Patients with the favourable CC genotype at rs12979860 have a more than twofold likelihood of spontaneous $\mathrm{HCV}$ clearance compared with heterozygotes (CT) and homozygotes (TT) (67). The CC genotype is also associated with an approximately twofold increase in SVR to PEGIFN and RBV therapy compared with the unfavourable SNPs in patients with HCV genotype $1(68,70)$. The relevance in genotypes 2 and 3 and in treatment-experienced patients is less clear. There is marked ethnic variation in the prevalence of the IL28B genotypes.

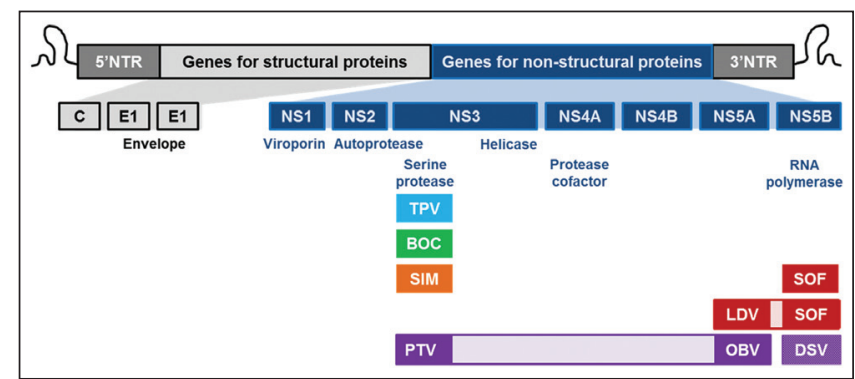

Figure 2) Hepatitis $\mathrm{C}$ virus genome and the polyprotein targets of newly approved, direct-acting antiviral agents. Note: Sofosbuvir (SOF) is a nucleotide nonstructural protein (NS)5B polymerase inhibitor and dasabuvir (DSV) is a non-nucleoside polymerase inhibitor. BOC Boceprevir; LDV Ledipasvir; OBV Ombitasvir; PTV Paritaprevir; SIM Simeprevir; TPV Telaprevir

The CC genotype is highly prevalent in Asians, but relatively uncommon in Africans, while Caucasians and Hispanics have an intermediate prevalence (68). Similar associations have been reported for the rs8099917 SNP (favourable allele $=\mathrm{T}$ and unfavourable allele $=\mathrm{G}$ ) (71), and for the recently described IFN-lambda 4 (IFNL4) SNP ss46915590 (favourable allele $=\mathrm{T}$ and unfavourable allele $=\Delta \mathrm{G})(72)$. For simplicity, further discussion will refer to the rs12979860 SNP.

The impact of the IL28B genotype on treatment success is lower when treatment includes DAAs. Patients with the CC genotype have a very high rate of SVR when treated with DAAs plus PEG-IFN and RBV, reaching 98\% with sofosbuvir (SOF)-based triple therapy for HCV genotype 1 (5). DAAs lead to a greater relative increase in SVR in non-CC patients. While the IL28B genotype is of limited importance with respect to SVR rates with IFN-free regimens $(8,15)$, whether patients with the favourable IL28B genotype will be able to shorten therapy or use fewer DAAs is unclear.

\section{Recommendations:}

12. The IL28B genotype may provide valuable information regarding the likelihood of SVR depending on the HCV genotype and therapy under consideration (Class 2b, Level A).

13. A nonfavourable IL28B genotype does not preclude antiviral therapy (Class 1, Level A).

\section{DAAs}

Multiple steps in the HCV life cycle have proven attractive targets for novel pharmacological therapies (Figure 2). Particularly promising agents target the NS3/4A serine protease, the NS5B RNA-dependent RNA polymerase and the NS5A protein (73). The first DAAs approved by Health Canada for the treatment of HCV genotype 1 were the NS3/4A PIs, BOC and TVR. A second-generation PI, simeprevir (SIM), was approved in 2013 for use in combination with PEG-IFN and RBV for genotype 1. In 2013, the first HCV nucleotide polymerase inhibitor, SOF, was approved for use in combination with PEG-IFN and RBV for genotypes 1 and 4 and with RBV alone for genotypes 2 and 3. In 2014, the single-tablet regimen of SOF combined with the NS5A inhibitor ledipasvir (LDV) was approved for patients with HCV genotype 1, including those previously treated with BOC and TVR. In addition, the combination of the ritonavirboosted PI paritaprevir $\left(\mathrm{PTV}_{\mathrm{R}}\right)$, the NS5A inhibitor ombitasvir $(\mathrm{OBV})$, and the non-nucleoside polymerase inhibitor dasabuvir (DSV) with or without RBV was approved for patients with HCV genotype 1 . Given the markedly improved efficacy and tolerability of these regimens, all patients would benefit from IFN-free therapy. Therefore, these newly approved agents are recommended as first-line therapy for all indications throughout these guidelines. However, access to IFN-free regimens is not universal across Canada. Whether to initiate therapy with an IFN-containing regimen or wait for the availability of all-oral regimens is an individualized decision that must 
consider the patient's wishes, the urgency of therapy, the severity of liver disease, the anticipated tolerability of PEG-IFN, the likelihood of SVR and the expected timeline for access to IFN-free regimens.

\section{TREATMENT-NAIVE PATIENTS WITH HCV GENOTYPE 1 (TABLE 4)}

\section{PEG-IFN-free regimens}

SOF/LDV: The nucleotide polymerase inhibitor SOF $(400 \mathrm{mg}$ ) has been combined with the NS5A inhibitor LDV $(90 \mathrm{mg})$ in a single tablet regimen (SOF/LDV) administered once daily. This combination was evaluated in treatment-naive patients in the open-label ION-1 (8) and ION-3 (10) phase 3 trials with a primary end point of SVR12. In the ION-1 study, which included patients with compensated cirrhosis (16\%), participants were randomly assigned to 12 or 24 weeks of SOF/ LDV with or without weight-based RBV (8). Among patients who received SOF/LDV for 12 weeks, SVR12 rates were 97\% (211 of 217) and $99 \%$ (211 of 214) in those who received and did not receive RBV, respectively. In the 24-week treatment arms, SVR12 rates were $99 \%$ (215 of 217) in RBV-treated patients compared with 98\% (212 of 217) in those who received SOF/LDV alone. There were no statistically significant differences between treatment arms or pretreatment characteristics that were predictive of response. Among the 136 cirrhotic patients, SVR 12 rates ranged from $94 \%$ to $100 \%$, with no differences between 12 and 24 weeks or with or without RBV. The IL28B genotype was not predictive of response; SVR12 rates ranged from $97 \%$ to $99 \%$ among patients with the unfavourable non-CC genotype. Only one patient experienced virological breakthrough on therapy and two patients relapsed. All three of these patients had NS5A resistance, but no SOF resistance was detected by deep sequencing. Although the majority of patients complained of at least one adverse event, $93 \%$ were mild to moderate in severity with the most common being fatigue, headache, insomnia and nausea. Adverse events were more common in patients randomized to receive RBV. No patient receiving SOF/LDV alone had a hemoglobin concentration $<100 \mathrm{~g} / \mathrm{L}$.

In the ION-3 study (10), treatment-naive, noncirrhotic patients with $\mathrm{HCV}$ genotype 1 were randomly assigned to eight weeks of SOF/ LDV with or without weight-based RBV, or SOF/LDV alone for 12 weeks. Among the 215 patients randomly assigned to SOF/LDV for eight weeks, 202 (94\%) achieved SVR12, compared with 201 of 216 (93\%) who received SOF/LDV/RBV for eight weeks, and 206 of $216(95 \%)$ who received SOF/LDV for 12 weeks. The relapse rates were $5 \%(\mathrm{SOF} / \mathrm{LDV})$ and $4 \%(\mathrm{SOF} / \mathrm{LDV} / \mathrm{RBV})$ in the eight-week treatment arms and $1 \%$ in the 12 -week treatment arm. Although the 12-week regimen had a lower relapse rate, treating all patients for an additional four weeks would lead to overtreatment of the majority of individuals. Therefore, a post hoc analysis of baseline viral load was conducted to identify patients in whom an eight-week regimen would suffice (74). In this analysis, patients with an HCV RNA level $<6$ million $\mathrm{IU} / \mathrm{mL}$ had a $2 \%$ relapse rate in both the eight-week (two of 123 ) and 12-week (two of 131) SOF/LDV treatment arms, and SVR12 rates of $97 \%$ (119 of 123 ) and 96\% (126 of 131), respectively. However, in patients with a baseline viral load $\geq 6$ million $\mathrm{IU} / \mathrm{mL}$, those treated for only eight weeks with SOF/LDV had a 10\% (nine of 92) relapse rate versus only $1 \%$ (one of 85 ) if treated for 12 weeks. Corresponding SVR12 rates were 90\% (83 of 92) and 94\% (80 of 85 ), respectively. Based on these findings, Health Canada and the United States Food and Drug Administration (FDA) have recommended an eight-week regimen of SOF/LDV in treatment-naive, noncirrhotic patients with baseline HCV RNA $<6$ million IU/mL and 12 weeks in patients with a higher viral load (74).

In addition to baseline viral load, the impact of baseline RAVs on treatment response was examined (10). Although 15 of 23 relapsers $(65 \%)$ to SOF/LDV had NS5A-resistant variants detected at the time of relapse (present at baseline in nine patients), SOF resistance was not identified. Among 116 patients (18\%) with NS5A resistance at baseline, 90\% achieved SVR12, suggesting a minimal impact of baseline NS5A RAVs on treatment response with SOF/LDV.

\section{Recommendations: \\ 14. In noncirrhotic, treatment-naive patients with HCV genotype 1, SOF/LDV should be given for eight weeks (Class 1, Level B). \\ 15. In noncirrhotic, treatment-naive patients with genotype 1 and baseline HCV RNA $\geq 6$ million IU/mL, extension of SOF/LDV therapy to 12 weeks can be considered (Class 1 , Level C). \\ 16. In cirrhotic, treatment-naive patients with genotype 1 , SOF/LDV should be given for 12 weeks (Class 1, Level B).}

$\mathrm{PTV}_{\mathrm{R}} / \mathrm{OBV} / \mathrm{DSV} \pm \mathrm{RBV}$ : The PI PTV is given with low-dose ritonavir $\left(\mathrm{PTV}_{\mathrm{R}}\right)$ to permit once-daily dosing. PTV $\mathrm{R}_{\mathrm{R}}(150 \mathrm{mg} / 100 \mathrm{mg})$ and the NS5A inhibitor OBV (25 mg) are coformulated in a single tablet taken as two tablets once daily. This tablet is combined with the nonnucleoside polymerase inhibitor DSV $(250 \mathrm{mg})$ taken as one tablet twice daily. Placebo or the combination of the three DAAs plus ritonavir (referred to as the '3D' regimen) and weight-based RBV was given for 12 weeks to treatment-naive, noncirrhotic patients with HCV genotype 1 in the phase 3 SAPPHIRE-I trial (15). Patients randomly assigned to placebo subsequently received active treatment. Of 473 patients who started active therapy, 455 (96\%) achieved SVR12, clearly superior to a historical control of TVR-based triple therapy in a similar patient population (estimated SVR12 of 78\%). SVR12 did

\section{TABLE 4}

Treatment-naive patients with hepatitis C virus (HCV) genotype 1

\begin{tabular}{|c|c|c|c|c|}
\hline Population & Recommended & Alternative (IFN-free) & Alternative (IFN-containing) & Not recommended \\
\hline \multirow[t]{3}{*}{ Genotype 1a, noncirrhotic } & SOF/LDV $\times 8-12$ weeks ${ }^{*}$ & SOF/SIM $\times 12$ weeks & SOF/PEG/RBV $\times 12$ weeks & PEG/RBV \\
\hline & $\mathrm{PTV}_{\mathrm{R}} / \mathrm{OBV} / \mathrm{DSV} / \mathrm{RBV} \times 12$ weeks & & SIM/PEG/RBV $\times 24$ weeks & PEG/RBV/BOC or TVR \\
\hline & & & (if Q80K-) & SIM/PEG/RBV $\times 24$ weeks (if Q80K+) \\
\hline Genotype $1 \mathrm{~b}$, noncirrhotic & $\mathrm{PTV}_{\mathrm{R}} / \mathrm{OBV} / \mathrm{DSV} \times 12$ weeks & & SIM/PEG/RBV $\times 24$ weeks & $\mathrm{PEG} / \mathrm{RBV} / \mathrm{BOC}$ or TVR \\
\hline \multirow[t]{2}{*}{ Genotype 1a, cirrhotic } & SOF/LDV $\times 12$ weeks & SOF/SIM $\times 12$ weeks & SOF/PEG/RBV $\times 12$ weeks & PEG/RBV \\
\hline & $\mathrm{PTV}_{\mathrm{R}} / \mathrm{OBV} / \mathrm{DSV} / \mathrm{RBV} \times 12$ weeks & & SIM/PEG/RBV $\times 24-48$ weeks & $\mathrm{PEG} / \mathrm{RBV} / \mathrm{BOC}$ or TVR \\
\hline \multirow[t]{2}{*}{ Genotype $1 \mathrm{~b}$, cirrhotic } & SOF/LDV $\times 12$ weeks & SOF/SIM $\times 12$ weeks & SOF/PEG/RBV $\times 12$ weeks & PEG/RBV \\
\hline & $\mathrm{PTV}_{\mathrm{R}} / \mathrm{OBV} / \mathrm{DSV} / \mathrm{RBV} \times 12$ weeks & & SIM/PEG/RBV $\times 24$ weeks & $\mathrm{PEG} / \mathrm{RBV} / \mathrm{BOC}$ or TVR \\
\hline
\end{tabular}

*In noncirrhotic, treatment-naive patients with HCV genotype 1a or 1b, treat with sofosbuvir/ledipasvir (SOF $400 \mathrm{mg} / \mathrm{LDV} 90 \mathrm{mg}$ ) once daily (one tablet) for eight weeks. Consider 12 weeks of treatment if baseline HCV RNA $\geq 6$ million IU/mL. + Positive; - Negative; BOC Boceprevir; DSV Dasabuvir (250 mg) one tablet twice

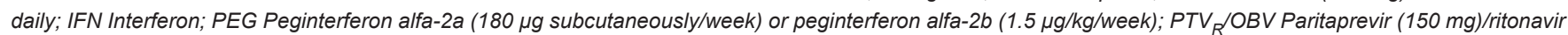
(100 mg)/ombitasvir (25 mg) two tablets once daily; Q80K Simeprevir-associated resistance variant at position $80 ;$ RBV Ribavirin (weight-based dosing: 1000 mg daily if <75 kg; 1200 mg daily if $\geq 75$ kg); SIM Simeprevir (150 mg once daily); SOF Sofosbuvir (400 mg once daily); TVR Telaprevir 
not differ between patients with HCV genotype 1a (95\% [307 of 322]) or $1 \mathrm{~b}$ ( $98 \%$ [148 of 151]). The only baseline factor associated with response was body mass index (BMI). Obese patients (BMI $\geq 30 \mathrm{~kg} / \mathrm{m}^{2}$ ) had an SVR12 rate of $91.5 \%$ compared with $97 \%$ in patients with a lower BMI. There was no difference in response according to IL28B genotype, fibrosis stage, baseline HCV RNA level, ethnicity or RBV dose modification.

Safety of the regimen was evaluated by comparing with patients randomly assigned to placebo (15). Adverse events were more common in those on active treatment (88\%); however, $73 \%$ of placebotreated patients also experienced at least one adverse event. Severe adverse events $(2.1 \%)$, in particular those requiring drug discontinuation $(<1 \%)$, were rare. The most common side effects were fatigue and headache, but were no more frequent with active treatment than placebo. Nausea, pruritus, insomnia, diarrhea and asthenia were reported more frequently in patients on active treatment. Total bilirubin elevations were seen in $2.8 \%$ of patients on this regimen, likely due to RBVrelated hemolysis and inhibition of the bilirubin transporters OATP1B1 and OATP1B3 by PTV . No episodes of hepatotoxicity were reported. Grade 2 anemia (hemoglobin $80 \mathrm{~g} / \mathrm{L}$ to $100 \mathrm{~g} / \mathrm{L}$ ) was reported in $5.8 \%$ of patients treated with this regimen including RBV. In $5.5 \%$ of patients, the RBV dose was modified due to adverse events, but no impact on the rate of SVR12 was observed in these patients.

The TURQUOISE-II phase 3 trial evaluated the PTV $\mathrm{R}_{\mathrm{R}} / \mathrm{OBV} / \mathrm{DSV}$ plus RBV regimen (12 versus 24 weeks) in treatment-naive and treatment-experienced patients with compensated cirrhosis (13). Among treatment-naive patients, the rates of SVR12 were similar between the 12- and 24-week arms (94\% [81 of 86] versus 95\% [70 of 74]) and by genotype subtype (genotype 1a: 12 versus 24 weeks: $92 \%$ [59 of 64] versus $93 \%$ [52 of 56]; and genotype 1 b: $100 \%$ in both the 12 -week [22 of 22] and 24-week [18 of 18] groups). SVR12 rates among previously treated patients from TURQUOISE-II are discussed below.

To evaluate the importance of RBV administration with $\mathrm{PTV}_{\mathrm{R}} /$ OBV/DSV, the PEARL-III and PEARL-IV phase 3 trials were conducted in treatment-naive, noncirrhotic patients with genotypes $1 \mathrm{~b}$ and 1a, respectively (75). In PEARL-III, patients with HCV genotype $1 \mathrm{~b}$ were randomly assigned to receive $\mathrm{PTV}_{\mathrm{R}} / \mathrm{OBV} / \mathrm{DSV}$ alone $(\mathrm{n}=209)$ or with RBV $(n=210)$ for 12 weeks. Only three of 419 patients in the trial failed treatment; the SVR12 rate was $99 \%$ in both groups. In the PEARL-IV trial, of 205 patients with HCV genotype 1a randomly assigned to receive $\mathrm{PTV}_{\mathrm{R}} / \mathrm{OBV} / \mathrm{DSV}$ alone for 12 weeks, 185 (90\%) achieved SVR12; this rate was significantly lower than that observed in patients treated with $\mathrm{PTV}_{\mathrm{R}} / \mathrm{OBV} / \mathrm{DSV}$ plus RBV (97\% [97 of 100]), emphasizing the importance of RBV coadministration when this regimen is prescribed to patients with HCV genotype 1a (75).

\section{Recommendations:}

17. In treatment-naive patients with HCV genotype 1a infection, with or without cirrhosis, and for those with genotype $1 \mathrm{~b}$ infection and cirrhosis, coformulated $\mathrm{PTV}_{\mathrm{R}} / \mathrm{OBV} / \mathrm{DSV}$ should be given with weight-based RBV for 12 weeks (Class 1, Level A).

18. In noncirrhotic, treatment-naive patients with genotype $1 \mathrm{~b}$ infection, coformulated $\mathrm{PTV}_{\mathrm{R}} / \mathrm{OBV} / \mathrm{DSV}$ should be given without RBV for 12 weeks (Class 1, Level A).

SOF and SIM: SOF (400 mg daily) was combined with the secondgeneration PI SIM (150 mg daily) with or without RBV for 12 or 24 weeks in the phase 2 COSMOS study (76). The study was divided into two cohorts: cohort 1 included 80 null responders with mild fibrosis (F0 to F2) and cohort 2 included 87 treatment-naive and null responders with advanced fibrosis (F3 and F4). HCV RNA was suppressed on treatment in all patients, but six patients relapsed. The overall SVR12 rate was $92 \%$ (154 of 167), with similar results in cohorts 1 and 2 (90\% [72 of 80 ] versus $94 \%$ [ 82 of 87 ], respectively). The SVR12 rates did not differ between 12 and 24 weeks of treatment, with or without RBV, or in treatment-naive versus treatment-experienced patients (95\% [38 of 40] versus $91 \%$ [116 of 127]). The presence of a polymorphism at position 80 with a substitution of a $\mathrm{K}$ (lysine) for $\mathrm{Q}$ (glutamine), referred to as the 'Q80K' polymorphism, which is associated with reduced activity of SIM and found almost exclusively in patients with HCV genotype 1a (see below) (77,78), did not impact the rate of SVR12 (76). Although four of the six relapsers had genotype 1a infection and the Q80K polymorphism at baseline, $88 \%$ (51 of 58 ) of patients with this polymorphism still achieved SVR12. In this small trial, the regimen was well tolerated; headache, fatigue and nausea were the most commonly reported side effects. Only four patients (2\%) discontinued treatment due to adverse events. Although the results from this trial are encouraging, given its small sample size and the availability of other effective and less expensive all-oral antiviral regimens, this regimen should be considered as a second-line option until further data emerge.

\section{Recommendation:}

19. In treatment-naive patients with HCV genotype $1 \mathrm{a}$ or $1 \mathrm{~b}$ infection, with or without cirrhosis, SOF (400 mg daily) and SIM (150 mg daily) should be given for 12 weeks without RBV (Class 1, Level B).

\section{PEG-IFN-containing regimens}

Given the efficacy and markedly improved tolerability of SOF or SIM combined with PEG-IFN and RBV compared with TVR- or BOCbased regimens, the latter first-generation PIs should no longer be used except in rare circumstances where treatment is urgent and access to newer agents is not available. The use of BOC and TVR is reviewed in the 2012 version of the present guidelines (3).

SOF, PEG-IFN and RBV: SOF (400 mg daily) was combined with PEG-IFN and RBV for 12 weeks in patients with HCV genotypes 1,4 5 and 6 in the uncontrolled, open-label, phase 3 NEUTRINO trial (5). Among patients with HCV genotype 1, the SVR12 rate was 89\% (261 of 292). Although a higher proportion of patients with genotype 1a achieved SVR12 than those with genotype 1b (92\% [206 of 225] versus $82 \%$ [54 of 66]), this difference was not statistically significant. In multivariate analysis, the presence of cirrhosis and a non-CC IL28B genotype were the only predictors of virological failure. The SVR12 rate was $92 \%$ ( 252 of 273 ) in noncirrhotic patients versus $80 \%$ (43 of 54 ) in patients with compensated cirrhosis. The SVR 12 rate was $98 \%$ (93 of 95) in patients with the IL28B CC genotype, compared with $87 \%$ (202 of 232) in those with a non-CC genotype. Although the side effect profile appeared similar to that of PEG-IFN and RBV dual therapy, the uncontrolled nature of the study precluded a clear evaluation of safety. However, only $2 \%$ of patients discontinued treatment due to an adverse event. Among the 28 patients who relapsed (9\% of the cohort), resistance to SOF was not detected by deep sequencing (5).

\section{Recommendation:}

20. In patients with HCV genotype $1 \mathrm{a}$ or $1 \mathrm{~b}$, with or without cirrhosis, SOF (400 mg daily) should be given with PEG-IFN plus weight-based RBV for 12 weeks (Class 1 , Level B).

SIM, PEG-IFN and RBV: In the QUEST-1 and QUEST-2 phase 3 trials $(6,7)$, conducted in North America and Europe, respectively, the second-generation PI SIM (150 mg once daily) was combined with PEG-IFN and weight-based RBV for 12 weeks followed by an additional 12 or 36 weeks of PEG-IFN plus RBV and compared with PEGIFN plus RBV for 48 weeks in patients with HCV genotype 1. Patients randomly assigned to triple therapy who had HCV RNA $<25 \mathrm{IU} / \mathrm{mL}$ at week 4 and undetectable HCV RNA at week 12 continued PEGIFN plus RBV for 12 additional weeks and then stopped all treatment. Patients who did not meet these early response criteria continued PEG-IFN and RBV for an additional 36 weeks (ie, 48 weeks total). In pooled data from these trials, the SVR12 rate in the SIM/PEG-IFN/ RBV groups was $80 \%$ (419 of 521), significantly higher than in 
patients receiving PEG-IFN and RBV alone (50\% [132 of 264]) $(6,7)$. In total, $88 \%$ (459 of 521) of patients in the SIM/PEG-IFN/RBV groups qualified for shortened therapy and $88 \%$ (405 of 459) of these patients achieved SVR12. In the two trials, of the 12\% (62 of 521) of patients who did not qualify for shortened therapy, the SVR12 rate was 32\% despite up to 36 weeks of additional PEG-IFN and RBV. SVR12 rates differed according to baseline fibrosis level, decreasing from 84\% (317 of 378 ) in patients with $\mathrm{F} 0$ to $\mathrm{F} 2$ fibrosis to $60 \%$ ( 29 of 48 ) in those with cirrhosis. The IL28B genotype was also important, with SVR12 rates of 95\% (144 of 152) in CC patients treated with triple therapy compared with $80 \%$ (63 of 79) with PEG-IFN and RBV alone, and 75\% (275 of $369)$ in patients with a non-CC genotype who received triple therapy compared with $37 \%$ (69 of 185) in the control arm.

The most important predictor of response was the presence of the Q80K polymorphism at baseline (described above). In pooled data from these trials $(6,7)$, the SVR12 rate with SIM-based triple therapy was $58 \%$ (49 of 84 ) in patients with genotype 1a and Q80K; no different than that seen in the PEG-IFN and RBV control arm (52\% [23 of 44]). In contrast, among patients with genotype 1a infection without Q80K, the SVR12 rate was 84\% (138 of 165), similar to that seen in patients with genotype $1 \mathrm{~b}$ infection ( $85 \%$ [228 of 267]) and significantly higher than found in the control arms (43\% [36 of 83] in genotype 1a without Q80K and 53\% [70 of 133] in genotype 1b). In these trials, the Q80K polymorphism was present at baseline in $34 \%$ of patients with genotype 1a infection and available sequencing data, but in only one of 400 patients with genotype $1 b(6,7)$. Rates of Q80K positivity among patients with HCV genotype 1a in Canada have been reported to be as high as $47 \%$ (79).

SIM was well tolerated in these trials $(6,7)$. In pooled data across the SIM study program (80), the main adverse events seen more frequently in SIM-treated patients were rash (mostly mild) seen in $23 \%$ of patients (versus $17 \%$ of controls) and photosensitivity in $3.3 \%$ (versus $0.5 \%$ of controls). Total bilirubin elevation, which is due to inhibition of biliary transporters and RBV-related hemolytic anemia, was observed in $7.9 \%$ of patients (versus $2.8 \%$ of controls). Notably, the incidence of anemia was similar among patients treated with SIMbased triple therapy versus PEG-IFN and RBV alone.

\section{Recommendations:}

21. In patients with $\mathrm{HCV}$ genotype $1 \mathrm{~b}$ infection and patients with genotype 1a infection without the Q80K polymorphism, SIM (150 mg daily) should be given with PEG-IFN plus weightbased RBV for 12 weeks followed by an additional 12 weeks of PEG-IFN plus RBV (Class 1, Level A).

22. Patients with genotype 1a infection must be tested for the Q80K polymorphism before starting therapy with SIM, PEGIFN and RBV. Patients with the Q80K polymorphism should be treated with an alternative regimen (Class 1, Level A).

23. RGT should not be used with SIM, PEG-IFN and RBV. Patients who have HCV RNA $\geq 25 \mathrm{IU} / \mathrm{mL}$ at week 4 or detectable HCV RNA at week 12 should stop all therapy given the low probability of SVR and the need for prolonged exposure to PEG-IFN and RBV (Class 2b, Level C).

\section{TREATMENT-EXPERIENCED PATIENTS WITH HCV GENOTYPE 1 (TABLE 5)}

\section{PEG-IFN-free regimens}

Patients who have failed IFN-based therapy should be categorized as relapsers (undetectable HCV RNA during treatment with reappearance of HCV RNA within six months of stopping therapy), partial responders (decline of at least $2 \log _{10} \mathrm{IU} / \mathrm{mL}$ in HCV RNA without ever achieving undetectable HCV RNA during therapy), or null responders $\left(<2 \log _{10} \mathrm{IU} / \mathrm{mL}\right.$ decline in HCV RNA during therapy; or breakthrough [increase by $>1 \log _{10} \mathrm{IU} / \mathrm{mL}$ in HCV RNA above nadir despite ongoing antiviral therapy]) (3). Patients with an unknown previous response should be managed as null responders. As in treatment-naive patients, all previously treated patients with HCV genotype 1 would benefit from all-oral DAA regimens rather than those containing IFN because these patients, with the exception of relapsers, have demonstrated poor IFN responsiveness.

SOF/LDV: The single tablet regimen of SOF/LDV was evaluated in treatment-experienced patients in the ION-2 phase 3 trial (9). The study included relapsers (56\%) and nonresponders (44\%), including patients who had failed PEG-IFN/RBV dual therapy (48\%) or in combination with a PI (52\%). Patients were randomly assigned to receive 12 or 24 weeks of treatment with or without weight-based RBV. The SVR12 rate was 94\% (102 of 109) in patients who received 12 weeks of SOF/LDV and 96\% (107 of 111) in those who also received RBV. The SVR12 rate in patients who received 24 weeks of SOF/LDV therapy was $99 \%$ (218 of 220 overall) whether the patients also received RBV. Virological relapse occurred in $4 \%$ to $6 \%$ of patients treated for 12 weeks, but in none treated for 24 weeks. The SVR12 rate in patients with compensated cirrhosis (20\% of each treatment arm) treated for 12 weeks with SOF/LDV alone was $86 \%$ (19 of 22 ) versus $82 \%$ (18 of 22 ) in those who also received RBV. In cirrhotic patients treated for 24 weeks (with or without RBV), the SVR12 rate was 100\% (44 of 44). No baseline or on-treatment predictors of relapse were identified in patients with cirrhosis. There were no differences in SVR12 rates according to receipt of $\mathrm{RBV}$, previous antiviral regimen (PEG-IFN/RBV versus PEG-IFN/RBV plus a PI), or previous treatment response (relapse versus nonresponse). Among the 62 patients (14\%) with detectable NS5A resistance at baseline, 55 (89\%) achieved an SVR12. All 11 patients who relapsed had detectable NS5A resistance at the time of relapse, but $\mathrm{SOF}$-associated resistance was not detected. Among patients previously treated with a PI-containing regimen, $71 \%$ had NS3/4A resistance at baseline and $98 \%$ of these patients achieved an SVR12 (9). Tolerability of SOF/LDV was similar to that observed in the ION-1 and ION-3 studies (see above) $(8,10)$; more adverse events were reported in patients treated with RBV.

Based on the higher rates of response observed in the ION-2 trial among previous treatment failure patients with compensated cirrhosis treated for 24 versus 12 weeks, Health Canada and the FDA have recommended a 24-week regimen of SOF/LDV in this patient subgroup. However, a subsequent and significantly larger randomized trial from France (the SIRIUS trial) (81) suggested that a 12-week regimen of SOF/LDV plus weight-based RBV is as effective as a 24-week SOF/ LDV regimen in patients with cirrhosis who had failed both PEG-IFN/ RBV and triple therapy including a PI. Specifically, 74 of 77 patients (96\%) randomly assigned to SOF/LDV/RBV for 12 weeks had an SVR12 (4\% relapse rate) compared with 75 of 77 patients (97\%) randomly assigned to SOF/LDV alone for 24 weeks (3\% relapse rate). Furthermore, in a pooled analysis of data from the SIRIUS trial and six other phase 2 and 3 studies that included 352 treatment-experienced patients with cirrhosis (82), 12 weeks of SOF/LDV/RBV resulted in a similar SVR12 rate to 24 weeks of SOF/LDV alone (96\% versus $98 \%$ ).

\section{Recommendations:}

24. In noncirrhotic patients with HCV genotype 1 who have failed previous therapy with PEG-IFN and RBV, with or without a $\mathrm{PI}, \mathrm{SOF} / \mathrm{LDV}$ without RBV should be given for 12 weeks (Class 1, Level B).

25. In cirrhotic patients with genotype 1 who have failed previous therapy with PEG-IFN and RBV, with or without a PI, SOF/ LDV and weight-based RBV should be given for 12 weeks (Class 1, Level A).

$\mathrm{PTV}_{\mathrm{R}} / \mathrm{OBV} / \mathrm{DSV}$ and RBV: The combination of $\mathrm{PTV}_{\mathrm{R}} / \mathrm{OBV} / \mathrm{DSV}$ with weight-based RBV was evaluated in treatment-experienced patients without cirrhosis in the SAPPHIRE-II phase 3 trial (14). Among 297 patients randomly assigned to $\mathrm{PTV}_{\mathrm{R}} / \mathrm{OBV} / \mathrm{DSV}$ plus RBV regimen for 12 weeks, 286 (96\%) achieved SVR12. No pre- or ontreatment predictors of response were identified. The SVR12 rate was 
TABLE 5

Treatment-experienced patients with hepatitis C virus (HCV) genotype 1

\begin{tabular}{|c|c|c|c|c|}
\hline Population & Recommended & Alternative (IFN-free) & Alternative (IFN-containing) & Not recommended \\
\hline \multirow[t]{3}{*}{ Genotype $1 \mathrm{a}$, noncirrhotic } & SOF/LDV $\times 12$ weeks & SOF/SIM $\times 12$ weeks $^{\dagger}$ & SOF/PEG/RBV $\times 12$ weeks & PEG/RBV \\
\hline & $\mathrm{PTV}_{\mathrm{R}} / \mathrm{OBV} / \mathrm{DSV} / \mathrm{RBV} \times 12$ weeks & & SIM/PEG/RBV $\times 24-48$ weeks (if Q80K-) ${ }^{\dagger \ddagger}$ & PEG/RBV/BOC or TVR \\
\hline & & & & SIM/PEG/RBV (if Q80K+) \\
\hline Genotype $1 \mathrm{~b}$, noncirrhotic & $\mathrm{PTV}_{\mathrm{R}} / \mathrm{OBV} / \mathrm{DSV} \times 12$ weeks & & SIM/PEG/RBV $\times 24-48$ weeks ${ }^{\dagger, \ddagger}$ & PEG/RBV/BOC or TVR \\
\hline \multirow[t]{2}{*}{ Genotype 1a, cirrhotic } & SOF/LDV/RBV $\times 12$ weeks & SOF/LDV $\times 24$ weeks & SOF/PEG/RBV $\times 12$ weeks & PEG/RBV \\
\hline & $\begin{array}{l}\mathrm{PTV}_{\mathrm{R}} / \mathrm{OBV} / \mathrm{DSV} / \mathrm{RBV} \times 12-24 \\
\text { weeks*}\end{array}$ & SOF/SIM $\times 12$ weeks $^{\dagger}$ & $\mathrm{SIM} / \mathrm{PEG} / \mathrm{RBV} \times 24-48$ weeks (if Q80K-) ${ }^{\dagger \ddagger}$ & $\begin{array}{l}\text { PEG/RBV/BOC or TVR } \\
\text { SIM/PEG/RBV if Q80K+) }\end{array}$ \\
\hline \multirow[t]{2}{*}{ Genotype $1 \mathrm{~b}$, cirrhotic } & SOF/LDV/RBV $\times 12$ weeks & SOF/LDV $\times 24$ weeks & SOF/PEG/RBV $\times 12$ weeks & PEG/RBV \\
\hline & $\mathrm{PTV}_{\mathrm{R}} / \mathrm{OBV} / \mathrm{DSV} / \mathrm{RBV} \times 12$ weeks & SOF/SIM $\times 12$ weeks $^{\dagger}$ & SIM/PEG/RBV $\times 24-48$ weeks ${ }^{\dagger \ddagger}$ & PEG/RBV/BOC or TVR \\
\hline
\end{tabular}

${ }^{*}$ Patients with HCV genotype 1 a, cirrhosis and previous null response should receive 24 weeks of PTV ${ }_{R} / O B V / D S V / R B V$ (paritaprevir//ritonavir/ombitasvir/dasabuvir/ ribavirin) if treated with this regimen. Relapsers and partial responders with genotype 1 and cirrhosis can be treated for 12 weeks with PTV $V_{R}(O B V / D S V / R B V$; †Simeprevir (SIM)-containing regimens should not be given to patients who have failed previous therapy with a protease inhibitor; $¥$ Previous null responders with genotype $1 a$ or $1 b$ should not be treated with SIM/ Peginterferon alfa-2a or peginterferon alfa-2b (PEG)/RBV regardless of the presence or absence of cirrhosis. Previous relapsers should be treated for 24 weeks total (12 weeks of SIM/PEG/RBV followed by 12 weeks of PEG/RBV) if HCV RNA <25 IU/mL at week 4 and undetectable at week 12. Otherwise, all treatment should be discontinued. Partial responders should be treated for 48 weeks total (12 weeks of SIM/PEG/RBV followed by 36 weeks of PEG/RBV) if HCV RNA $<25 \mathrm{IU} / \mathrm{mL}$ at week 4 and undetectable at weeks 12 and 24; otherwise, all treatment should be discontinued. + Positive; - Negative; BOC Boceprevir; DSV: 250 mg one tablet twice daily; IFN Interferon; PEG: Peginterferon alfa-2a (180 $\mu g$ subcutaneously/week) or peginterferon alfa-2b (1.5 $\mu \mathrm{g} / \mathrm{kg} /$ week); PTV $R$ /OBV: $150 \mathrm{mg} / 100 \mathrm{mg} / 25 \mathrm{mg}$, two tablets once daily; Q80K SIM-associated resistance variant at position 80; RBV weight-based dosing: $1000 \mathrm{mg}$ daily if <75 kg; $1200 \mathrm{mg}$ daily if $\geq 75 \mathrm{~kg}$; SIM: $150 \mathrm{mg}$ once daily; SOF Sofosbuvir (400 mg once daily); SOF/LDV SOF 400 mg/ledipasvir 90 mg once daily (one tablet); TVR Telaprevir

similar between patients with genotype 1a (96\% [166 of 173]) and $1 \mathrm{~b}$ (97\% [119 of 123]), and did not differ between relapsers (95\% [82 of 86]), partial responders (100\% [65 of 65]) and null responders $(95 \%$ [139 of 146]). RAVs to one or more of the three DAAs in the regimen were detected in five of the seven patients with post-treatment relapse (14).

In the TURQUOISE-II trial (13), $\mathrm{PTV}_{\mathrm{R}} / \mathrm{OBV} / \mathrm{DSV}$ plus RBV regimen for 12 or 24 weeks was evaluated in 380 patients with compensated cirrhosis, of whom $58 \%$ had previously failed PEG-IFN and RBV therapy. Among patients with genotype 1b, the SVR12 rate was $99 \%$ (67 of 68 ) with 12 weeks of therapy and $100 \%$ (51 of 51 ) with 24 weeks. Response rates did not differ according to treatment duration or previous treatment history. In patients with genotype 1a infection, SVR12 rates were $89 \%$ (124 of 140) with 12 weeks and $94 \%$ (114 of 121) with 24 weeks of therapy; this difference was not statistically significant. There was no difference between the 12- and 24-week study arms among treatment-naive, cirrhotic patients with genotype 1a (12 versus 24 weeks: $92 \%$ [59 of 64] versus 93\% [52 of 56]), previous relapsers (93\% [14 of 15] versus $100 \%$ [13 of 13]) or partial responders (100\% [11 of 11$]$ versus $100 \%$ [10 of 10]). However, among null responders with genotype 1a, the 24-week arm was superior to 12 weeks of treatment ( $93 \%$ [39 of 42] versus $80 \%$ [40 of 50]) (13).

To determine the importance of RBV in noncirrhotic, treatmentexperienced patients with HCV genotype $1 \mathrm{~b}$ infection, the PEARL-II study randomly assigned patients to receive $\mathrm{PTV}_{\mathrm{R}} / \mathrm{OBV} / \mathrm{DSV}$ with or without RBV for 12 weeks (83). All 91 patients (100\%) who received $\mathrm{PTV}_{\mathrm{R}} / \mathrm{OBV} / \mathrm{DSV}$ alone achieved SVR12 compared with 97\% (85 of 88) randomly assigned to also receive RBV.

There is expected to be overlap between RAVs due to PI-based therapies. Because the PTV $\mathrm{R}_{\mathrm{R}} / \mathrm{OBV} / \mathrm{DSV}$ regimen contains a PI and other regimens with documented activity in these patients are available (ie, SOF/LDV) (9), this regimen should not be used in patients who have failed another PI (eg, TVR, BOC or SIM).

\section{Recommendations:}

26. In noncirrhotic, treatment-experienced patients with HCV genotype 1a infection, coformulated $\mathrm{PTV}_{\mathrm{R}} / \mathrm{OBV} / \mathrm{DSV}$ should be given with weight-based RBV for 12 weeks (Class 1, Level A).

27. In noncirrhotic, treatment-experienced patients with genotype $1 \mathrm{~b}$ infection, coformulated $\mathrm{PTV} \mathrm{R}_{\mathrm{R}} / \mathrm{OBV} / \mathrm{DSV}$ should be given without RBV for 12 weeks (Class 1, Level A).
28. In cirrhotic patients with genotype 1a infection and a history of previous null response to PEG-IFN and RBV, coformulated $\mathrm{PTV}_{\mathrm{R}} / \mathrm{OBV} / \mathrm{DSV}$ should be given with RBV for 24 weeks (Class 1, Level B).

29. In patients who have failed therapy with another PI, coformulated $\mathrm{PTV}_{\mathrm{R}} / \mathrm{OBV} / \mathrm{DSV}$ should not be given due to the potential for cross-resistance with PTV (Class 2b, Level C).

SOF and SIM: As previously described, SOF (400 mg daily) was combined with the PI SIM (150 mg daily) with or without RBV for 12 or 24 weeks in the phase 2 COSMOS study (76). Cohort 1 included 80 null responders with mild fibrosis (F0 to F2) and cohort 2 included 47 null responders (plus 40 treatment-naive patients) with advanced fibrosis (F3 and F4). Overall, 116 of 127 null responders (91\%) achieved an SVR12, not significantly different from that observed among treatment-naive subjects ( $95 \%$ [38 of 40]). SVR12 rates among null responders were similar regardless of fibrosis severity (F0 to F2: 90\% [72 of 80] versus F3: 96\% [23 of 24] versus F4: 91\% [21 of 23]), treatment duration or receipt of RBV. Given the expected crossresistance between other PIs and SIM, patients who previously failed treatment with these agents were excluded from the study (76). Because of the small sample size of this trial and the availability of other effective and less expensive IFN-free regimens, this combination should be considered as a second line option until further data emerge.

\section{Recommendations:}

30. In patients with HCV genotype $1 \mathrm{a}$ or $1 \mathrm{~b}$ infection, with or without cirrhosis, who have failed previous therapy with PEGIFN and RBV, SOF (400 mg daily) and SIM (150 mg daily) should be given without RBV for 12 weeks (Class 1, Level B).

31. The combination of SOF and SIM should not be used in patients who have failed therapy with another PI (Class 2b, Level C).

\section{PEG-IFN-containing regimens}

Given the efficacy and markedly improved safety and tolerability of SOF and SIM combined with PEG-IFN and RBV compared to TVR or BOC-based regimens, these first generation PIs should no longer be used except in rare circumstances (see above). 
SOF, PEG-IFN and RBV: Experience with the use of SOF (400 mg) in combination with PEG-IFN and RBV in patients who have failed IFNbased therapy is limited. Nevertheless, Health Canada and the United States FDA have approved this regimen for treatment-experienced patients. Based on a modelling approach, the FDA projected an SVR12 rate of $78 \%$ in PEG-IFN and RBV treatment failures if retreated with SOF plus PEG-IFN/RBV for 12 weeks. In the NEUTRINO phase 3 trial of treatment-naive patients (5), 52 patients with HCV genotype 1 had characteristics typical of the treatment-experienced population (ie, advanced fibrosis [F3 and F4], a non-CC IL28B genotype and high baseline viral load $[\geq 800,000 \mathrm{IU} / \mathrm{mL}])$. Thirty-seven of these patients $(71 \%)$ achieved SVR12 with 12 weeks of SOF/PEG-IFN/RBV (74). Although this regimen is also untested in patients who have failed therapy with a PI, the absence of cross-resistance between the PIs and SOF suggests that these patients should respond similarly to those who failed treatment with PEG-IFN/RBV alone.

\section{Recommendation:}

32. In patients with HCV genotype 1a or 1b infection, with or without cirrhosis, who have failed previous therapy with PEGIFN and RBV with or without a PI, SOF (400 mg daily) should be given with PEG-IFN plus weight-based RBV for 12 weeks (Class 2b, Level C).

SIM, PEG-IFN and RBV: SIM (150 mg daily) has been evaluated in combination with PEG-IFN and weight-based RBV for 12 weeks followed by an additional 12 to 36 weeks of PEG-IFN and RBV in patients with HCV genotype 1 who failed IFN-based therapy in two trials. The phase 3 PROMISE study (84) included relapsers, whereas the phase $2 \mathrm{~b}$ ASPIRE trial (85) also included partial and null responders. In the PROMISE trial (84), an RGT approach identical to that used in treatment-naive patients was evaluated (see above). Treatment with triple therapy was more effective than PEG-IFN and RBV dual therapy (SVR12: 79\% [206 of 260] versus 36\% [48 of 133]) in these relapsers. The majority of SIM-treated patients (93\% [241 of 260]) were eligible to shorten treatment from 48 to 24 weeks and $83 \%$ of these patients (200 of 241) achieved SVR12. In patients with undetectable HCV RNA at week 4 (77\% of the cohort), the SVR12 rate was $87 \%$ (173/200), compared with $60 \%$ in those with HCV RNA $<25 \mathrm{IU} / \mathrm{mL}$ but detectable at week 4 . Among patients who did not qualify for shortened therapy, the SVR12 rate was $40 \%$ (six of 15 ) despite 48 weeks of treatment. Of the 39 patients with compensated cirrhosis randomly assigned to triple therapy, 29 (74\%) achieved SVR12 compared with five of 19 (26\%) in the control arm. As reported in treatment-naive subjects from the QUEST-1 and QUEST-2 trials (6,7), patients with HCV genotype 1a and the Q80K mutation at baseline did not benefit from SIM treatment (SVR12 rates in the simeprevir and placebo arms: $47 \%$ [14 of 30] versus 30\% [six of 20], respectively). RAVs similar to those selected by TVR and BOC emerged in most patients (90\%) who did not achieve SVR12 in the SIM arm (84).

In the phase 2b ASPIRE trial (85), 462 patients who failed PEGIFN/RBV therapy (40\% relapsers, $35 \%$ partial responders and $25 \%$ null responders) were randomly assigned to receive SIM (100 mg or $150 \mathrm{mg}$ or placebo) for 12, 24 or 48 weeks in combination with PEGIFN and RBV for 48 weeks. In patients treated with SIM $150 \mathrm{mg}$ daily for 12 weeks, SVR24 rates were 77\% (20 of 26) in relapsers, $65 \%$ (15 of 23 ) in partial responders and $44 \%$ (eight of 18 ) in null responders; all superior to rates in the control arm (37\%, 19\% and 9\%, respectively). Among null responders with cirrhosis (across all SIM $150 \mathrm{mg}$ arms), $31 \%$ (four of 13) achieved SVR24 with SIM compared with neither of two patients treated with PEG-IFN and RBV.

\section{Recommendations:}

33. In patients with HCV genotype 1b or genotype 1a infection without the Q80K polymorphism who relapsed to PEG-IFN and RBV, SIM (150 mg daily) should be given with PEG-IFN and weight-based RBV for 12 weeks followed by PEG-IFN plus RBV for an additional 12 weeks. All therapy should be discontinued in patients who have HCV RNA $>25 \mathrm{IU} / \mathrm{mL}$ at week 4 or detectable HCV RNA at week 12 (Class 1, Level A).

34. In patients with previous partial or null response, alternative regimens should be considered given the low probability of SVR and the need for prolonged exposure to PEG-IFN and $\mathrm{RBV}$ with this regimen (Class $2 \mathrm{~b}$, Level B).

\section{PATIENTS WITH HCV GENOTYPE 2 (TABLE 6) \\ SOF and RBV}

In the phase 3 FISSION trial (5), SOF (400 mg daily) was administered in combination with weight-based RBV for 12 weeks to treatmentnaive patients with $\mathrm{HCV}$ genotype 2. Patients randomly assigned to the control arm received a 24-week course of PEG-IFN and RBV ( $800 \mathrm{mg}$ daily). Patients with cirrhosis accounted for approximately $20 \%$ of the study population. The SVR 12 rates in the SOF/RBV and PEG-IFN/RBV arms were $97 \%$ (68 of 70) and 78\% (52 of 67), respectively. The incidence of adverse events was consistently lower among patients who received SOF/RBV, particularly the influenza-like symptoms and depression characteristic of IFN-based therapy. In the phase 3 VALENCE trial (12), 32 treatment-naive patients with HCV genotype 2 received a 12 -week regimen of SOF and weight-based RBV. As observed in the FISSION study (5), all but one of these patients (97\%) achieved an SVR12. The response rate did not differ between cirrhotic (100\% [two of two]) and noncirrhotic patients (97\% [29 of 30]). In the phase 3 POSITRON trial (11), 143 IFN-ineligible patients with HCV genotype 2 were randomly assigned to receive SOF and weight-based RBV for 12 weeks or placebo. The majority of patients in this trial had contraindications to or refused IFN therapy; only $7 \%$ had previously

\section{TABLE 6}

\section{Patients with hepatitis $\mathrm{C}$ virus genotype 2}

\begin{tabular}{|c|c|c|c|c|}
\hline Population & Recommended & Alternative (IFN-free) & Alternative (IFN-containing) & Not recommended \\
\hline \multirow[t]{3}{*}{ Treatment-naive } & SOF/RBV $\times 12$ weeks & None & SOF/PEG/RBV $\times 12$ weeks & PEG/RBV/PI \\
\hline & & & PEG/RBV $\times 24$ weeks $^{*}$ & SOF/LDV \\
\hline & & & & $\mathrm{PTV}_{\mathrm{R}} / \mathrm{OBV} / \mathrm{DSV} \pm \mathrm{RBV}$ \\
\hline Treatment-experienced, noncirrhotic & SOF/RBV $\times 12$ weeks & None & SOF/PEG/RBV $\times 12$ weeks & PEG/RBV \\
\hline \multirow[t]{3}{*}{ Treatment-experienced, cirrhotic } & SOF/PEG/RBV $\times 12$ weeks & SOF/RBV $\times 16$ weeks $^{*}$ & None & PEG/RBV/PI \\
\hline & & & & SOF/LDV \\
\hline & & & & SOF/SIM \\
\hline
\end{tabular}

${ }^{*}$ Clinically inferior regimen. DSV Dasabuvir (250 mg) one tablet twice daily; IFN Interferon; PEG Peginterferon alfa-2a (180 $\mu$ g subcutaneously/week) or peginter-

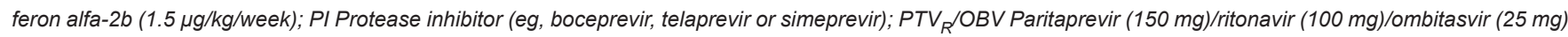
two tablets once daily; RBV Ribavirin (weight-based dosing [1000 mg daily if <75 kg; $1200 \mathrm{mg}$ daily if $\geq 75 \mathrm{~kg}$ ] if combined with sofosbuvir (SOF); $800 \mathrm{mg}$ daily if used in dual therapy with PEG); SIM Simeprevir (150 mg daily); SOF: 400 mg daily; SOF/LDV SOF $400 \mathrm{mg} / \mathrm{ledipasvir} 90 \mathrm{mg}$ once daily (one tablet) 
failed IFN-based treatment. Among 109 patients with genotype 2 treated with SOF/RBV for 12 weeks, 101 patients (93\%) achieved an SVR12, similar to results observed in the FISSION and VALENCE trials $(5,12)$. SVR12 rates did not differ between patients with and without cirrhosis (94\% [16 of 17 ] versus 92\% [ 85 of 92]).

SOF (400 mg daily) and weight-based RBV has also been studied in treatment-experienced patients with $\mathrm{HCV}$ genotype 2 in the VALENCE (12) and FUSION (11) phase 3 trials. In VALENCE (12), 37 of $41(90 \%)$ treatment-experienced patients had an SVR12 following a 12-week course of SOF/RBV. In the FUSION trial (11), 68 patients who had previously failed an IFN-containing regimen (approximately $75 \%$ due to relapse), were randomly assigned to receive SOF/RBV for either 12 or 16 weeks. Overall, an SVR12 was observed in $86 \%$ ( 31 of 36 ) of patients treated for 12 weeks versus $94 \%$ (30 of 32) treated for 16 weeks, although this difference was not statistically significant. In patients without cirrhosis, high rates of SVR12 were observed regardless of treatment duration (12 versus 16 weeks: $96 \%$ [25 of 26] versus $100 \%$ [23 of 23]). However, lower rates of response were observed among patients with cirrhosis (12 versus 16 weeks: $60 \%$ [six of 10] versus $78 \%$ [seven of nine]). Although this difference was not statistically significant, the poor response rate among patients treated for 12 weeks suggests that a 16-week regimen is preferred if $\mathrm{SOF} / \mathrm{RBV}$ is prescribed to this patient subgroup, particularly in IFNineligible subjects. Tolerability of $\mathrm{SOF} / \mathrm{RBV}$ was similar to that observed in the FISSION and POSITRON studies $(5,11)$

\section{SOF, PEG-IFN and RBV}

SOF, PEG-IFN, and weight-based RBV for 12 weeks has been studied in patients with $\mathrm{HCV}$ genotype 2 who failed previous therapy in an open-label phase 2 study (86). Among 23 patients with HCV genotype 2 (14 with cirrhosis), an SVR12 rate of 96\% (22 of 23) was observed. High rates of response were observed among cirrhotic (93\% [13 of 14]) and noncirrhotic patients (100\% [nine of nine]). Among the entire study population $(n=47)$, which also included 24 patients with genotype 3 , three patients discontinued RBV due to anemia and one patient discontinued all therapy due to pain. Serious adverse events occurred in four patients $(9 \%)$; the majority were considered due to PEG-IFN or RBV and none due to SOF

\section{Recommendations:}

35. In treatment-naive patients with HCV genotype 2, SOF (400 mg daily) should be given with weight-based RBV for 12 weeks (Class 1, Level A).

36. In noncirrhotic, treatment-experienced patients with genotype 2, SOF (400 mg daily) should be given with weightbased RBV for 12 weeks (Class 1, Level A).

37. In IFN-eligible, treatment-experienced patients with genotype 2 and cirrhosis, SOF (400 mg daily) should be given with PEG-IFN and weight-based RBV for 12 weeks. In IFNineligible patients, SOF (400 mg daily) should be given with weight-based RBV for 16 weeks (Class 1 , Level B).

\section{PATIENTS WITH HCV GENOTYPE 3 (TABLE 7) SOF and RBV}

In the phase 3 FISSION trial (5), SOF (400 mg daily) in combination with weight-based RBV for 12 weeks or PEG-IFN/RBV ( $800 \mathrm{mg}$ daily) for 24 weeks were administered to 359 treatment-naive patients with HCV genotype 3. Overall, an SVR12 was observed in 56\% (102 of 183 ) of patients randomly assigned to receive SOF/RBV compared with $63 \%$ (110 of 176) in those treated with PEG-IFN/RBV. This difference was not statistically significant. In light of the suboptimal responses observed with a 12 -week SOF/RBV regimen in this trial, the VALENCE trial examined a 24-week course in patients with HCV genotype 3 (12). Among treatment-naive patients, 94\% (99 of 105) achieved an SVR12; responses did not differ between cirrhotic $(92 \%$ [12 of 13]) and noncirrhotic patients (95\% [87 of 92]).

SOF/RBV combination therapy has also been studied in treatment-experienced patients with HCV genotype 3. In the FUSION phase 3 trial (11), 127 patients who had failed previous treatment were randomly assigned to 12 or 16 weeks of SOF and weight-based RBV. Overall, SVR 12 rates were $30 \%$ (19 of 64) and 62\% (39 of 63) in the 12 - and 16-week groups, respectively. The presence of cirrhosis was a strong negative predictor of response in patients treated for 12 weeks; only $19 \%$ (five of 26 ) of cirrhotic patients and 37\% (14 of 38) of noncirrhotic patients had an SVR12 with this regimen. In the 16-week treatment arm, SVR12 rates were $61 \%$ (14 of 23 ) among patients with cirrhosis and $63 \%$ ( 25 of 40 ) in those without cirrhosis. In this trial, the primary mode of treatment failure was relapse, which was observed among 66\% (42 of 64) of patients treated for 12 weeks and 38\% (24 of 63 ) of those treated for 16 weeks. Therefore, the VALENCE trial examined a longer course ( 24 weeks) of SOF/RBV therapy in 145 treatmentexperienced patients with HCV genotype 3 (12). Among 98 noncirrhotic patients in this trial, an SVR12 was observed in 85 (87\%). However, only $62 \%$ (29 of 47 ) of patients with cirrhosis had an SVR12. Based on these data, alternative treatment options are necessary in cirrhotic, treatment-experienced patients with HCV genotype 3.

\section{SOF, PEG-IFN and RBV}

SOF, PEG-IFN and weight-based RBV administered for 12 weeks was studied in patients with HCV genotype 3 who failed previous therapy in a small, open-label phase 2 study (86). Among 24 patients, 12 of whom had cirrhosis, an SVR12 rate of $83 \%$ (20 of 24) was observed. There was no difference in response between cirrhotic and noncirrhotic patients ( $83 \%$ [10 of 12$]$ in both groups).

\section{SOF/LDV plus RBV}

The single tablet regimen of SOF/LDV has been studied in patients with HCV genotype 3 in the open-label, phase 2, ELECTRON-2 trial conducted in two centres in New Zealand (87). In this study, 51 treatment-naive patients ( $16 \%$ with cirrhosis) were randomly assigned to 12 weeks of SOF/LDV with or without weight-based RBV. Fifty treatment-experienced patients (44\% with cirrhosis) all received SOF/LDV plus RBV. Among treatment-naive patients, SVR12 rates were $64 \%$ (16 of 25 ) in the SOF/LDV group and $100 \%$ (26 of 26 ) in those who received SOF/LDV plus RBV. In treatment-experienced patients

\section{TABLE 7}

\section{Patients with hepatitis C virus genotype 3}

\begin{tabular}{|c|c|c|c|c|}
\hline Population & Recommended & Alternative (IFN-free) & Alternative (IFN-containing) & Not recommended \\
\hline Treatment-naive, noncirrhotic & SOF/RBV $\times 24$ weeks & SOF/LDV/RBV $\times 12$ weeks & $\begin{array}{l}\text { SOF/PEG/RBV × } 12 \text { weeks } \\
\text { PEG/RBV } \times 24 \text { weeks* }\end{array}$ & $\begin{array}{l}\mathrm{PEG} / \mathrm{RBV} / \mathrm{PI} \\
\mathrm{PTV}_{\mathrm{R}} / \mathrm{OBV} / \mathrm{DSV} \pm \mathrm{RBV} \\
\text { SOF/SIM }\end{array}$ \\
\hline Treatment-naive, cirrhotic & SOF/RBV $\times 24$ weeks & SOF/LDV/RBV × 12 weeks & SOF/PEG/RBV × 12 weeks & PEG/RBV \\
\hline Treatment-experienced, noncirrhotic & SOF/RBV $\times 24$ weeks & SOF/LDV/RBV $\times 12$ weeks & SOF/PEG/RBV × 12 weeks & PEG/RBV/PI \\
\hline Treatment-experienced, cirrhotic & SOF/PEG/RBV × 12 weeks & $\begin{array}{l}\text { SOF/RBV } \times 24 \text { weeks* } \\
\text { SOF/LDV/RBV } \times 12 \text { weeks }\end{array}$ & None & $\begin{array}{l}\mathrm{PTV}_{\mathrm{R}} / \mathrm{OBV} / \mathrm{DSV} \pm \mathrm{RBV} \\
\mathrm{SOF} / \mathrm{SIM}\end{array}$ \\
\hline
\end{tabular}

*Approved, but clinically inferior regimen. DSV Dasabuvir (250 mg) one tablet twice daily; IFN Interferon; PEG Peginterferon alfa-2a (180 $\mu$ g subcutaneously/week) or peginterferon alfa-2b (1.5 $\mathrm{gg} / \mathrm{kg} /$ week); PI Protease inhibitor (eg, boceprevir, telaprevir or simeprevir); PTV ${ }_{R} / O B V$ Paritaprevir (150 mg)/ritonavir (100 mg)/ombitasvir (25 mg) two tablets once daily; RBV Ribavirin (weight-based dosing [1000 mg daily if <75 kg; $1200 \mathrm{mg}$ daily if $\geq 75 \mathrm{~kg}$ ] if combined with sofosbuvir (SOF); $800 \mathrm{mg}$ daily if used in dual therapy with PEG); SIM Simeprevir (150 mg daily); SOF: $400 \mathrm{mg}$ daily; SOF/LDV SOF (400 mg)/ledipasvir (90 mg) once daily (one tablet) 
treated with SOF/LDV/RBV for 12 weeks, noncirrhotic patients had higher SVR12 rates than those with cirrhosis ( $89 \%$ [25 of 28] versus $73 \%$ [16 of 22]). LDV has limited activity against genotype $3 \mathrm{HCV}$ in vitro (88); therefore, although $\mathrm{SOF} / \mathrm{LDV}$ is a potential therapeutic option in these patients, additional data in diverse populations are necessary before it can be recommended as first-line therapy over other SOF-containing regimens.

\section{Recommendations:}

38. In treatment-naive patients and noncirrhotic treatmentexperienced patients with HCV genotype 3, SOF (400 mg daily) should be given with weight-based RBV for 24 weeks (Class 1, Level B).

39. In cirrhotic, treatment-experienced patients with HCV genotype 3, SOF (400 mg daily) should be given with PEGIFN and weight-based RBV for 12 weeks (Class 1, Level B).

\section{PATIENTS WITH HCV GENOTYPES 4, 5 AND 6 (TABLE 8)}

There are limited data to guide treatment decision-making for patients with HCV genotypes 4, 5 or 6 due to the small numbers of patients enrolled in phase 3 clinical trials. In Canada, these genotypes are present in $<1 \%$ of cases (22). Although the first-generation PIs, BOC and TVR, do not have clinically significant activity against genotypes 4, 5 or 6, SOF (5) and SIM (89) have activity against all of these genotypes. However, due to a paucity of published data, Health Canada and the United States FDA have approved only SOF for the treatment of HCV genotype 4.

\section{PEG-IFN-free regimens}

$\mathrm{PTV}_{\mathrm{R}} / \mathrm{OBV} \pm \mathrm{RBV}$ : The fixed-dose combination of the ritonavirboosted, NS3/4A PI PTV $\mathrm{R}_{\mathrm{R}}$ and the NS5A inhibitor OBV was studied in patients with HCV genotype 4 in the PEARL-I study (90). Treatment-naive patients were randomly assigned to receive $P T V_{R} /$ OBV with or without weight-based RBV for 12 weeks; all treatmentexperienced patients received RBV. Nearly all patients (93\%) in this study had mild fibrosis (FO to F2) and none had cirrhosis. Among subjects who received $P T V_{R} / O B V$ plus RBV, all treatment-naive (42 of 42) and treatment-experienced patients (41 of 41) achieved an SVR12. However, the SVR12 rate was lower (91\% [40 of 44]) among treatment-naive patients randomly assigned to the RBV-free regimen, suggesting that RBV is necessary with this drug combination. The safety profile of PTV $V_{R} / O B V$ plus RBV was similar to that observed in patients with HCV genotype 1 who were also treated with DSV $(14,15)$.

SOF/LDV: The single tablet regimen of SOF/LDV was evaluated in patients with HCV genotype 4 in a single-center, open-label phase 2a trial (National Institutes of Allergy and Infectious Diseases SYNERGY) (91). Twenty-one patients (38\% treatment-experienced; $40 \%$ with cirrhosis) received SOF/LDV for 12 weeks. Among 20 patients who completed the post-treatment follow-up period, 19 (95\%) achieved SVR12. No patient discontinued treatment due to an adverse event. In a similar, open-label study conducted among 25 patients with HCV genotype 6 (92\% treatment-naive; 8\% with cirrhosis; 80\% IL28B CC genotype) from two centres (ELECTRON-2) (87), a 12-week regimen of SOF/LDV resulted in an SVR12 rate of 96\% (24 of 25). Although in vitro data suggest that SOF/LDV should be efficacious in patients with HCV genotype 5 (88), it cannot currently be recommended in this patient subgroup until clinical trial data are available.

SOF and RBV: The all-oral combination of SOF (400 mg daily) and weight-based RBV for 12 or 24 weeks was studied in a randomized trial conducted among 103 Egyptian patients with HCV genotype 4 (52\% treatment-experienced; $17 \%$ with compensated cirrhosis) (92). Among treatment-naive subjects, the SVR12 rates in the 12- and 24-week treatment arms were similar ( $84 \%$ [21 of 25] versus 92\% [22 of 24]). Whereas noncirrhotic patients had similar responses in the 12- and 24-week treatment arms (86\% [19 of 22] versus 90\% [19 of 21]), patients with cirrhosis appeared to benefit from prolonged therapy (SVR12 in 12- versus 24-week arms: 67\% [two of three] versus 100\% [three of three]); however, the sample size was limited. Among treatmentexperienced patients ( $41 \%$ nonresponders), a 24-week regimen was superior overall (SVR12 rates in 12-versus 24-week arms: 70\% [19 of 27] versus $89 \%$ [ 24 of 27]) and in noncirrhotic patients (73\% [16 of 22] versus $95 \%$ [20 of 21]). In patients with cirrhosis, SVR12 rates in the 12 - and 24-week treatment groups were 60\% (three of five) and 67\% (four of six), respectively (92). These results were supported by a small trial of Egyptian persons living in the United States treated with SOF and weight-based RBV for 12 or 24 weeks (93). In treatment-naive patients, the SVR12 rate was 79\% (11 of 14) in patients treated for 12 weeks and $100 \%$ (14 of 14) in those treated for 24 weeks. In treatment-experienced patients, corresponding SVR12 rates were 59\% (10 of $17)$ and $87 \%$ (13 of 15).

\section{PEG-IFN-containing regimens}

SOF, PEG-IFN and RBV: In the phase 2 ATOMIC study (94), SOF (400 mg once daily) was administered for 24 weeks in combination with PEG-IFN/RBV to a small number of patients with HCV genotypes 4 and 6 . SVR12 rates of $82 \%$ (nine of 11 ) in patients with genotype 4 and 100\% (five of five) in genotype 6 were observed, supporting the antiviral activity of this regimen. In the phase 3 NEUTRINO study (5), a small subset of patients with HCV genotypes $4(n=28)$, $5(n=1)$ and $6(n=5)$ received this regimen for a shorter 12 -week treatment period, and SVR12 rates of 96\% (27 of 28) in patients with genotype 4 and 100\% (six of six) for genotypes 5 and 6 were reported. The one patient with genotype 4 who failed to achieve an SVR12 had cirrhosis and relapsed after cessation of therapy. The tolerability was similar to that observed historically among patients treated with PEGIFN and RBV.

SIM, PEG-IFN and RBV: The RESTORE study was a phase 3, single-arm, open-label trial that evaluated SIM with PEG-IFN/RBV in 35 treatment-naive and 72 treatment-experienced patients with HCV genotype 4 (95). All patients received 12 weeks of triple therapy followed by 12 or 36 weeks of PEG-IFN and RBV dual therapy. Treatment-naive and relapser patients were eligible for RGT (an additional 12 weeks of PEG-IFN and RBV dual therapy if HCV RNA $<25 \mathrm{IU} / \mathrm{mL}$ at week 4 and undetectable at week 12; otherwise, an additional 36 weeks) while partial and null responders received 36 weeks of dual therapy (48 weeks total). Overall, 65\% (70 of 107) of patients achieved SVR12 ( $83 \%$ [29 of 35] of treatment-naive patients, $86 \%$ [19 of 22] of relapsers, $60 \%$ [six of 10] of partial responders and $40 \%$ [16 of 40] of null responders). The majority of patients ( $89 \%$ of treatment-naive and $91 \%$ of relapsers) met criteria for shortened therapy and SVR12 rates of $94 \%$ and $95 \%$ were observed in these groups, respectively. Safety was similar to that observed in other phase 3 trials of SIM/PEG-IFN/RBV therapy $(6,7)$.

\section{Recommendations:}

40. Patients with HCV genotype 4 should be treated with coformulated $\mathrm{PTV}_{\mathrm{R}} / \mathrm{OBV}$ plus weight-based RBV or SOF/LDV alone for 12 weeks (Class 1, Level B).

41. Patients with HCV genotype 5 should be treated with SOF (400 mg daily) and PEG-IFN plus weight-based RBV for 12 weeks (Class 1 , Level B).

42. Patients with HCV genotype 6 should be treated with SOF/ LDV for 12 weeks (Class 1, Level B).

\section{ANTIVIRAL RESISTANCE}

Emergence of RAVs must be considered with all DAA-based therapies. Due to the high replication rate of HCV and the low fidelity of its RNA-dependent RNA polymerase, new variants emerge continuously (96-98). HCV circulates as a large of population of related viruses known as quasispecies. Variants with mutations that lead to DAA resistance emerge by chance and are present at low frequencies 
TABLE 8

Patients with hepatitis C virus (HCV) genotypes 4, 5 and 6

\begin{tabular}{lllll}
\hline Population & Recommended & Alternative (IFN-free) & Alternative (IFN-containing) & Not recommended \\
\hline Genotype 4 & PTV $/$ RBV/RBV $\times 12$ weeks & SOF/RBV $\times 24$ weeks & SOF/PEG/RBV $\times 12$ weeks & PEG/RBV \\
& SOF/LDV $\times 12$ weeks & & SIM/PEG/RBV $\times 24-48$ weeks* & PEG/RBV/BOC or TVR \\
Genotype 5 & SOF/PEG/RBV $\times 12$ weeks & None & None & PTV ${ }_{R} / O B V / D S V \pm R B V$ \\
Genotype 6 & SOF/LDV $\times 12$ weeks & None & SOF/PEG/RBV $\times 12$ weeks & \\
\hline
\end{tabular}

${ }^{*}$ Treatment-naive and previous relapser patients with HCV genotype 4 should be treated for 24 weeks total (12 weeks of simeprevir/ peginterferon alfa-2a or peginterferon alfa-2b/ribavirin [SIM/PEG/RBV] followed by 12 weeks of PEG/RBV) if HCV RNA $<25$ IU/mL at week 4 and undetectable at week 12 . Otherwise, all treatment should be discontinued. Partial and null responders with HCV genotype 4 should be treated for 48 weeks total (12 weeks of SIM/PEG/RBV followed by 36 weeks of PEG/RBV) if HCV RNA <25 IU/mL at week 4 and undetectable at weeks 12 and 24; otherwise, all treatment should be discontinued. BOC Boceprevir; DSV Dasabuvir (250 mg) one tablet twice daily; IFN Interferon; PEG Peginterferon alfa-2a (180 $\mu$ g subcutaneously/week) or peginterferon alfa-2b (1.5 $\mu$ g/kg/week); PTV ${ }_{R}$ OBV Paritaprevir (150 mg)/ritonavir (100 mg)/ombitasvir (25 mg) two tablets once daily; RBV: weight-based dosing (1000 mg daily if <75 kg; $1200 \mathrm{mg}$ daily if $\geq 75 \mathrm{~kg}$ ); SIM: $150 \mathrm{mg}$ once daily; SOF Sofosbuvir (400 mg once daily); SOF/LDV SOF(400 mg)/ledipasvir (90 mg) once daily (one tablet); TVR telaprevir

before DAA exposure. With DAA exposure, these resistant variants have a selective advantage over wild-type virus and will emerge as the dominant strains in the quasispecies. The probability that resistance will emerge with particular DAAs depends on their genetic barrier to resistance. This barrier usually reflects the number of nucleotide substitutions that must occur for high-level resistance to emerge. For example, the common PI mutation, R155K, requires two substitutions in a genotype $1 \mathrm{~b}$ virus, but a single substitution in a genotype 1a virus and, consequently, this variant is much more common in patients with genotype 1a (99). In addition to the genetic barrier, the fitness of the RAV is important. A RAV that replicates very poorly is unlikely to emerge on therapy and will be quickly suppressed by wild-type virus once selective drug pressure is removed $(97,98)$. For example, the S282T variant that confers resistance to SOF has extremely low replicative fitness and, as a result, has been identified only rarely in patients during SOF therapy and quickly disappears on treatment cessation (100). In contrast, many variants resistant to NS5A inhibitors are very fit and compete well with wild-type virus $(88,101)$. As a result, NS5Aresistant variants are found in $10 \%$ to $15 \%$ of genotype 1 patients before drug exposure and persist long after therapy is discontinued in patients who fail an NS5A inhibitor-containing regimen $(8,9)$.

Strategies to overcome resistance include avoiding DAA monotherapy and DAA dose reductions, maximizing adherence, combining DAAs with nonoverlapping resistance profiles, choosing DAAs with high barriers to resistance, and combining DAAs with PEG-IFN and RBV (96). NS5A inhibitors (eg, LDV, OBV), non-nucleoside polymerase inhibitors (eg, DSV) and NS3/4A PIs (eg, TVR, BOC, SIM) have low barriers to resistance (88). However, when potent agents of multiple classes are combined, on-treatment virological failure is extremely rare (eg, one patient of 473 treated with $\mathrm{PTV}_{\mathrm{R}} / \mathrm{OBV} / \mathrm{DSV}$ plus RBV in the SAPPHIRE-I trial) and post-treatment relapse is very uncommon (eg, seven of 463 patients in this trial) (15). However, resistance to two or all three classes of drugs has been identified in almost all patients with virological failure on this combination. LDV-resistant variants are also uncommon, but present at the time of relapse in most patients who fail SOF/LDV combination therapy $(8,9)$.

There are no data to support pretreatment resistance testing. In patients who have failed a DAA-containing regimen, it is reasonable to assume that resistance to that DAA is present at the time of retreatment. Therefore, a regimen containing DAAs without overlapping resistance should be selected in this situation. For example, in patients who have failed TVR or BOC, SOF/LDV combination therapy is very effective. In the ION-2 trial (9), 159 of 163 patients (98\%) with persistent PI resistance at treatment initiation achieved an SVR12 with this regimen. Although RAVs may return to pretreatment levels after prolonged duration off therapy, there are no data on treating patients with PI resistance with a PI-containing regimen (eg, PTV $\mathrm{R}_{\mathrm{R}} / \mathrm{OBV} /$ DSV). Therefore, this approach should not be adopted, particularly given the presence of other proven alternatives (ie, SOF/LDV).

NS5A resistance is of slightly more concern because NS5A inhibitors are a component of most all-oral regimens (88). In patients with baseline NS5A resistance, 90\% achieved SVR12 with SOF/LDV in the ION-1 (8) and ION-3 (10) trials. Although this SVR rate was slightly lower than in patients without baseline resistance, the differences were not statistically significant and, therefore, pretreatment identification of resistance would not change management. Detailed baseline sequencing was not performed on all patients treated with the $\mathrm{PTV}_{\mathrm{R}} / \mathrm{OBV} / \mathrm{DSV}$ regimen in the phase 3 trials $(13-15,75,83)$; however, the rates of virological failure were low, suggesting that baseline NS5A resistance is unlikely to be a major issue. Whether retreatment of patients with emergent NS5A resistance with an NS5A-inhibitorcontaining regimen will be effective remains to be determined.

\section{Recommendations:}

43. DAAs should not be used as monotherapy (Class 1, Level B).

44. Dosage reductions of DAAs should not be used to manage treatment-related side effects (Class 2a, Level C).

45. Adherence with DAAs should be maximized to reduce the likelihood of resistance (Class 2a, Level C).

46. Patients who failed therapy with a PI in the past should be treated with a regimen that does not contain a PI (Class 1, Level B).

47. With the exception of testing for $\mathrm{Q} 80 \mathrm{~K}$ in patients being considered for treatment with SIM, PEG-IFN and RBV, there is no role for baseline resistance testing with current DAA regimens (Class 1 , Level A).

\section{DDIs}

Before the initiation of any DAA, potential DDIs must be considered, including those attributable to prescription and over-the-counter pharmaceuticals and herbal preparations. Identification of potential interactions requires knowledge of the metabolism of these agents. All currently available HCV PIs (TVR, BOC, SIM, PTV) are inhibitors and substrates of Cytochrome P450 3A4 (CYP3A4). Ritonavir, which is used to increase exposure and allow for once-daily dosing of PTV, is also an inhibitor and substrate of CYP3A4. Therefore, PIs are contraindicated with medications that are potent inducers of CYP3A4/5, which would reduce plasma concentrations and the therapeutic effect of the PI, and for those highly dependent on CYP3A4/5 for clearance, in which elevated plasma concentrations are associated with serious and/or life-threatening events (ie, a narrow therapeutic index). Other drug-metabolizing pathways are involved in individual PI handling that may affect DDIs. NS5A inhibitors and nucleotide polymerase inhibitors have fewer known DDIs than PIs; however, before starting therapy, all concomitant medications should be reviewed. Reference to an online updated database of DDIs is recommended before starting therapy (eg, http://www.hep-druginteractions.org).

\section{Recommendation:}

48. All prescription, over-the-counter and herbal medications should be reviewed for possible interactions with DAAs before starting therapy (Class 1, Level C). 


\section{FUTURE THERAPEUTIC OPTIONS}

Numerous additional antiviral agents are under investigation in various stages of clinical development, from phase 1 though premarketing approval. Promising DAAs include NS3/4A PIs (eg, asunaprevir, grazoprevir, sovaprevir, vedroprevir), NS5A inhibitors (eg, daclatasvir, GS-5816, elbasvir, ACH-3102 and samatasvir), and non-nucleoside (eg, beclabuvir and GS-9669) and nucleotide NS5B polymerase inhibitors (eg, MK-3682 and ACH-3422). As new data regarding these agents emerge, including their receipt of regulatory approval, these $\mathrm{HCV}$ management guidelines will be updated.

ACKNOWLEDGEMENTS: The authors would like to acknowledge members of the CASL Executive and CASL membership, particularly Drs Eberhard Renner, Rick Schreiber, Gisela Macphail, and Jerome Simon for helpful comments regarding this manuscript.

DISCLOSURES: Production of these guidelines was not supported by any third party. The authors report the following potential conflicts of interest: Dr Kelly Burak: Consulting fees from Astellas, Gilead Sciences, Janssen and Novartis. Speaking fees from Astellas. Research support from Bayer, Bristol-Myers Squibb and Oncozyme. Dr Curtis Cooper: Consulting fees from AbbVie, Boehringer-Ingelheim, Bristol-Myers Squibb, Gilead Sciences, Janssen, Merck, Roche Canada and Vertex. Speaking fees from AbbVie, Boehringer-Ingelheim, Gilead Sciences, Janssen and Roche Canada. Research support from AbbVie, Gilead Sciences and Vertex. Dr Jordan Feld: Consulting fees from AbbVie, Boehringer-Ingelheim, BristolMyers Squibb, Gilead Sciences, Janssen, Merck and Theravance. Research support from AbbVie, Boehringer-Ingelheim, Gilead Sciences, Janssen and Merck. Dr Robert Myers: Consulting fees from AbbVie, BoehringerIngelheim, Bristol-Myers Squibb, Gilead Sciences, GlaxoSmithKline, Janssen, Merck, Roche Canada and Vertex. Speaking fees from AbbVie, Boehringer-Ingelheim, Gilead Sciences, Janssen, Roche Canada and Vertex. Research support from Gilead Sciences and Vertex. Dr Hemant Shah: Consulting fees from AbbVie, Bristol-Myers Squibb, Gilead Sciences, Janssen and Merck. Speaking fees from AbbVie, Gilead Sciences, Janssen, Merck, Roche Canada and Vertex. Grant support from BoehringerIngelheim and Janssen.

\section{REFERENCES}

1. Shiffman RN, Shekelle P, Overhage JM, et al. Standardized reporting of clinical practice guidelines: a proposal from the Conference on Guideline Standardization. Ann Intern Med 2003;139:493-8.

2. American Heart Association. <http://my.americanheart.org/idc/ groups/ahamah-public/@wcm/@sop/documents/downloadable/ ucm_319826.pdf> (Accessed February 1, 2012).

3. Myers RP, Ramji A, Bilodeau M, Wong S, Feld JJ. An update on the management of hepatitis $\mathrm{C}$ : Consensus guidelines from the Canadian Association for the Study of the Liver. Can J Gastroenterol 2012;26:359-75.

4. Ghany MG, Nelson DR, Strader DB, Thomas DL, Seeff LB. An update on treatment of genotype 1 chronic hepatitis $C$ virus infection: 2011 practice guideline by the American Association for the Study of Liver Diseases. Hepatology 2011;54:1433-44.

5. Lawitz E, Mangia A, Wyles D, et al. Sofosbuvir for previously untreated chronic hepatitis C infection. N Engl J Med 2013;368:1878-87.

6. Manns M, Marcellin P, Poordad F, et al. Simeprevir with pegylated interferon alfa $2 \mathrm{a}$ or $2 \mathrm{~b}$ plus ribavirin in treatment-naive patients with chronic hepatitis C virus genotype 1 infection (QUEST-2): A randomised, double-blind, placebo-controlled phase 3 trial. Lancet 2014;384:414-26.

7. Jacobson IM, Dore GJ, Foster GR, et al. Simeprevir with pegylated interferon alfa 2a plus ribavirin in treatment-naive patients with chronic hepatitis $\mathrm{C}$ virus genotype 1 infection (QUEST-1): A phase 3, randomised, double-blind, placebo-controlled trial. Lancet 2014;384:403-13.

8. Afdhal N, Zeuzem S, Kwo P, et al. Ledipasvir and sofosbuvir for untreated HCV genotype 1 infection. N Engl J Med 2014;370:1889-98.

9. Afdhal N, Reddy KR, Nelson DR, et al. Ledipasvir and sofosbuvir for previously treated HCV genotype 1 infection. N Engl J Med 2014;370:1483-93.
10. Kowdley KV, Gordon SC, Reddy KR, et al. Ledipasvir and sofosbuvir for 8 or 12 weeks for chronic HCV without cirrhosis. N Engl J Med 2014;370:1879-88.

11. Jacobson IM, Gordon SC, Kowdley KV, et al. Sofosbuvir for hepatitis $\mathrm{C}$ genotype 2 or 3 in patients without treatment options. N Engl J Med 2013;368:1867-77.

12. Zeuzem S, Dusheiko GM, Salupere R, et al. Sofosbuvir and ribavirin in HCV genotypes 2 and 3. N Engl J Med 2014;370:1993-2001.

13. Poordad F, Hezode C, Trinh R, et al. ABT-450/r-ombitasvir and dasabuvir with ribavirin for hepatitis $\mathrm{C}$ with cirrhosis. N Engl J Med 2014;370:1973-82.

14. Zeuzem S, Jacobson IM, Baykal T, et al. Retreatment of HCV with ABT-450/r-ombitasvir and dasabuvir with ribavirin. N Engl J Med 2014;370:1604-14.

15. Feld JJ, Kowdley KV, Coakley E, et al. Treatment of HCV with ABT-450/r-ombitasvir and dasabuvir with ribavirin. N Engl J Med 2014;370:1594-603.

16. Hull M, Shafran S, Tseng A, et al. CIHR Canadian HIV Trials Network Co-Infection and Concurrent Diseases Core: Updated Canadian adult guidelines for the treatment of hepatitis $\mathrm{C}$ infection in HIV-hepatitis C coinfected patients. Can J Infect Dis Med Microbiol 2014;25:311-20.

17. Myers RP, Liu M, Shaheen AA. The burden of hepatitis $C$ virus infection is growing: A Canadian population-based study of hospitalizations from 1994 to 2004. Can J Gastroenterol 2008;22:381-7.

18. Myers RP, Krajden M, Bilodeau M, et al. Burden of disease and cost of chronic hepatitis C infection in Canada. Can J Gastroenterol Hepatol 2014;28:243-50.

19. Schanzer DL, Paquette D, Lix LM. Historical trends and projected hospital admissions for chronic hepatitis $\mathrm{C}$ infection in Canada: A birth cohort analysis. CMAJ 2014; Open 2:E139-144.

20. Rotermann M, Langlois K, Andonov A, Trubnikov M. Seroprevalence of hepatitis B and C virus infections: Results from the 2007 to 2009 and 2009 to 2011 Canadian Health Measures Survey. Health Rep 2013;24:3-13.

21. Remis RS. Modelling the incidence and prevalence of hepatitis $C$ infection and its sequelae in Canada, 2007. Final Report. <http:// www.phac-aspc.gc.ca/sti-its-surv-epi/model/pdf/model07-eng.pdf>. (Accessed February 1, 2012).

22. Antonishyn NA, Ast VM, McDonald RR, et al. Rapid genotyping of hepatitis $\mathrm{C}$ virus by primer-specific extension analysis. J Clin Microbiol 2005;43:5158-63.

23. Shah HA, Heathcote J, Feld JJ. A Canadian screening program for hepatitis C: Is now the time? CMAJ 2013;185:1325-8.

24. Pearlman BL, Traub N. Sustained virologic response to antiviral therapy for chronic hepatitis $\mathrm{C}$ virus infection: A cure and so much more. Clin Infect Dis 2011;52:889-900.

25. Yoshida EM, Sulkowski MS, Gane EJ, et al. Concordance of sustained virological response 4,12 , and 24 weeks post-treatment with sofosbuvir-containing regimens for hepatitis $\mathrm{C}$ virus. Hepatology 2014 [Epub ahead of print].

26. Maylin S, Martinot-Peignoux M, Moucari R, et al. Eradication of hepatitis $\mathrm{C}$ virus in patients successfully treated for chronic hepatitis C. Gastroenterology 2008;135:821-9.

27. Swain MG, Lai MY, Shiffman ML, et al. A sustained virologic response is durable in patients with chronic hepatitis $\mathrm{C}$ treated with peginterferon alfa-2a and ribavirin. Gastroenterology 2010;139:1593-601.

28. Myers RP, Cooper C, Sherman M, et al. Outcomes of chronic hepatitis $\mathrm{C}$ therapy in patients treated in community versus academic centres in Canada: Final results of APPROACH (a prospective study of peginterferon alfa-2a and ribavirin at academic and community centres in Canada). Can J Gastroenterol 2011;25:503-10.

29. Neary MP, Cort S, Bayliss MS, Ware JE Jr. Sustained virologic response is associated with improved health-related quality of life in relapsed chronic hepatitis $\mathrm{C}$ patients. Semin Liver Dis 1999;(19 Suppl 1):77-85.

30. Cacoub P, Ratziu V, Myers RP, et al. Impact of treatment on extra hepatic manifestations in patients with chronic hepatitis C. J Hepatol 2002;36:812-8.

31. Poynard T, McHutchison J, Manns M, et al. Impact of pegylated interferon alfa- $2 \mathrm{~b}$ and ribavirin on liver fibrosis in patients with chronic hepatitis C. Gastroenterology 2002;122:1303-13.

32. Poynard T, McHutchison J, Davis GL, et al. Impact of interferon alfa- $2 \mathrm{~b}$ and ribavirin on progression of liver fibrosis in patients with chronic hepatitis C. Hepatology 2000;32:1131-7. 
33. van der Meer AJ, Veldt BJ, Feld JJ, et al. Association between sustained virological response and all-cause mortality among patients with chronic hepatitis $\mathrm{C}$ and advanced hepatic fibrosis. JAMA 2012;308:2584-93.

34. Veldt BJ, Heathcote EJ, Wedemeyer $\mathrm{H}$, et al. Sustained virologic response and clinical outcomes in patients with chronic hepatitis C and advanced fibrosis. Ann Intern Med 2007;147:677-84.

35. Backus LI, Boothroyd DB, Phillips BR, et al. A sustained virologic response reduces risk of all-cause mortality in patients with hepatitis C. Clin Gastroenterol Hepatol 2011;9:509-516, e501.

36. Singal AG, Volk ML, Jensen D, Di Bisceglie AM, Schoenfeld PS. A sustained viral response is associated with reduced liver-related morbidity and mortality in patients with hepatitis $\mathrm{C}$ virus. Clin Gastroenterol Hepatol 2010;8:280-8, e281.

37. Jacobson IM, McHutchison JG, Dusheiko G, et al. Telaprevir for previously untreated chronic hepatitis $\mathrm{C}$ virus infection. N Engl J Med 2011;364:2405-16.

38. Sherman KE, Flamm SL, Afdhal NH, et al. Response-guided telaprevir combination treatment for hepatitis $\mathrm{C}$ virus infection. N Engl J Med 2011;365:1014-24.

39. Zeuzem S, Andreone P, Pol S, et al. Telaprevir for retreatment of HCV infection. N Engl J Med 2011;364:2417-28.

40. Poordad F, McCone J Jr, Bacon BR, et al. Boceprevir for untreated chronic HCV genotype 1 infection. N Engl J Med 2011;364:1195-206.

41. Bacon BR, Gordon SC, Lawitz E, et al. Boceprevir for previously treated chronic HCV genotype 1 infection. N Engl J Med 2011;364:1207-17.

42. MacParland SA, Bilodeau M, Grebely J, et al. The 3rd Canadian Symposium on Hepatitis C Virus: Expanding care in the interferonfree era. Can J Gastroenterol Hepatol 2014;28:481-7.

43. Intraobserver and interobserver variations in liver biopsy interpretation in patients with chronic hepatitis C. The French METAVIR Cooperative Study Group. Hepatology 1994;20:15-20.

44. Hellard M, Rolls DA, Sacks-Davis R, et al. The impact of injecting networks on hepatitis $\mathrm{C}$ transmission and treatment in people who inject drugs. Hepatology 2014;60:1861-70.

45. Micallef JM, Kaldor JM, Dore GJ. Spontaneous viral clearance following acute hepatitis $\mathrm{C}$ infection: A systematic review of longitudinal studies. J Viral Hepat 2006;13:34-41.

46. Sarrazin C, Kieffer TL, Bartels D, et al. Dynamic hepatitis C virus genotypic and phenotypic changes in patients treated with the protease inhibitor telaprevir. Gastroenterology 2007;132:1767-77.

47. Sherman KE, Sulkowski MS, Zoulim F, et al. Follow-up of SVR durability and viral resistance in patients with chronic hepatitis C treated with telaprevir-based regimens: Interim analysis of the EXTEND study (Abstract 248). Hepatology 2011;54(Suppl 4):485A.

48. Bedossa P. Liver biopsy. Gastroenterol Clin Biol 2008;32:4-7.

49. Myers RP, Fong A, Shaheen AA. Utilization rates, complications and costs of percutaneous liver biopsy: A population-based study including 4275 biopsies. Liver Int 2008;28:705-12.

50. Rockey DC, Caldwell SH, Goodman ZD, Nelson RC, Smith AD. Liver biopsy. Hepatology 2009;49:1017-44.

51. Guha IN, Myers RP, Patel K, Talwalkar JA. Biomarkers of liver fibrosis: What lies beneath the receiver operating characteristic curve? Hepatology 2011;54:1454-62.

52. Shaheen AA, Myers RP. Diagnostic accuracy of the aspartate aminotransferase-to-platelet ratio index for the prediction of hepatitis C-related fibrosis: A systematic review. Hepatology 2007;46:912-21.

53. Poynard T, Imbert-Bismut F, Munteanu M, et al. Overview of the diagnostic value of biochemical markers of liver fibrosis (FibroTest, HCV FibroSure) and necrosis (ActiTest) in patients with chronic hepatitis C. Comp Hepatol 2004;3:8.

54. Friedrich-Rust M, Ong MF, Martens S, et al. Performance of transient elastography for the staging of liver fibrosis: A metaanalysis. Gastroenterology 2008;134:960-974.

55. Myers RP, Elkashab M, Ma M, Crotty P, Pomier-Layrargues G. Transient elastography for the noninvasive assessment of liver fibrosis: A multicentre Canadian study. Can J Gastroenterol 24:661-70.

56. Myers RP, Pomier-Layrargues G, Kirsch R, et al. Feasibility and diagnostic performance of the FibroScan XL probe for liver stiffness measurement in overweight and obese patients. Hepatology 2012;55:199-208.

57. Castera L. Transient elastography and other noninvasive tests to assess hepatic fibrosis in patients with viral hepatitis.

J Viral Hepat 2009;16:300-14.
58. Venkatesh SK, Ehman RL. Magnetic resonance elastography of liver. Magn Reson Imaging Clin N Am 2014;22:433-46.

59. Ferraioli G, Tinelli C, Dal Bello B, et al. Accuracy of real-time shear wave elastography for assessing liver fibrosis in chronic hepatitis $\mathrm{C}$ : A pilot study. Hepatology 2012;56:2125-33.

60. Sebastiani G, Ghali P, Wong P, et al. Physicians' practices for diagnosing liver fibrosis in chronic liver diseases: A nationwide Canadian survey. Can J Gastroenterol Hepatol 2014;28:23-30.

61. Vergniol J, Foucher J, Terrebonne E, et al. Noninvasive tests for fibrosis and liver stiffness predict 5-year outcomes of patients with chronic hepatitis C. Gastroenterology 2011;140:1970-9, e1971-3.

62. Vergniol J, Boursier J, Coutzac C, et al. Evolution of noninvasive tests of liver fibrosis is associated with prognosis in patients with chronic hepatitis C. Hepatology 2014;60:65-76.

63. Pang JX, Zimmer S, Niu S, et al. Liver stiffness by transient elastography predicts liver-related complications and mortality in patients with chronic liver disease. PLoS One 2014;9:e95776.

64. Steadman R, Myers RP, Leggett L, et al. A health technology assessment of transient elastography in adult liver disease. Can J Gastroenterol 2013;27:149-58.

65. Poynard T, Ngo Y, Munteanu M, et al. Biomarkers of liver injury for hepatitis clinical trials: A meta-analysis of longitudinal studies. Antivir Ther 2010;15:617-31.

66. Vergniol J, Foucher J, Castera L, et al. Changes of non-invasive markers and FibroScan values during HCV treatment. J Viral Hepat 2009;16:132-40.

67. Thomas DL, Thio CL, Martin MP, et al. Genetic variation in IL28B and spontaneous clearance of hepatitis $\mathrm{C}$ virus. Nature 2009;461:798-801.

68. Ge D, Fellay J, Thompson AJ, et al. Genetic variation in IL28B predicts hepatitis $C$ treatment-induced viral clearance. Nature 2009;461:399-401.

69. Kurbanov F, Abdel-Hamid M, Latanich R, et al. Genetic polymorphism in IL28B is associated with spontaneous clearance of hepatitis $C$ virus genotype 4 infection in an Egyptian cohort. J Infect Dis 2011;204:1391-4.

70. Tanaka Y, Nishida N, Sugiyama M, et al. Genome-wide association of IL28B with response to pegylated interferon-alpha and ribavirin therapy for chronic hepatitis C. Nat Genet 2009;41:1105-9.

71. Suppiah V, Moldovan M, Ahlenstiel G, et al. IL28B is associated with response to chronic hepatitis $\mathrm{C}$ interferon-alpha and ribavirin therapy. Nat Genet 2009;41:1100-4.

72. Prokunina-Olsson L, Muchmore B, Tang W, et al. A variant upstream of IFNL3 (IL28B) creating a new interferon gene IFNL4 is associated with impaired clearance of hepatitis $C$ virus. Nat Genet 2013;45:164-71

73. Kronenberger B, Zeuzem S. New developments in HCV therapy. J Viral Hepat 2012;19(Suppl 1):48-51.

74. Gilead Sciences Inc. Product Monograph: Harvoni (Ledipasvir/ Sofosbuvir) Tablets $90 \mathrm{mg} / 400 \mathrm{mg}$ Antiviral Agent. <www.gilead. ca/pdf/ca/harvoni_pm_english.pdf $>$. October 14, 2014. (Accessed November 6, 2014).

75. Ferenci P, Bernstein D, Lalezari J, et al. ABT-450/r-ombitasvir and dasabuvir with or without ribavirin for HCV. N Engl J Med 2014;370:1983-92.

76. Lawitz E, Sulkowski MS, Ghalib R, et al. Simeprevir plus sofosbuvir, with or without ribavirin, to treat chronic infection with hepatitis $\mathrm{C}$ virus genotype 1 in non-responders to pegylated interferon and ribavirin and treatment-naive patients: The COSMOS randomised study. Lancet 2014;384:1756-65.

77. Bae A, Sun SC, Qi X, et al. Susceptibility of treatment-naive hepatitis $\mathrm{C}$ virus (HCV) clinical isolates to $\mathrm{HCV}$ protease inhibitors. Antimicrob Agents Chemother 2010;54:5288-97.

78. Paolucci S, Fiorina L, Piralla A, et al. Naturally occurring mutations to $\mathrm{HCV}$ protease inhibitors in treatment-naive patients. Virol J 2012;9:245.

79. Andonov A, Kadkhoda K, Osiowy C, Kaita K. Pretreatment resistance to hepatitis $\mathrm{C}$ virus protease inhibitors boceprevir/ telaprevir in hepatitis $\mathrm{C}$ virus subgenotype 1a-infected patients from Manitoba. Can J Gastroenterol 2013;27:414-6.

80. Antiviral Drugs Advisory Committee Meeting Briefing Document. Simeprevir (TMC435) Treatment of Patients with Chronic Hepatitis C. NDA 205123. October 24, 2013. <www.fda.gov/ downloads/AdvisoryCommittees/CommitteesMeetingMaterials/ Drugs/AntiviralDrugsAdvisoryCommittee/UCM371624.pdf>. (Accessed November 17, 2014). 
81. Bourliere M, Bronowicki JP, De Ledinghen V, et al. Ledipasvir/ sofosbuvir fixed dose combination is safe and efficacious in cirrhotic patients who have previously failed protease-inhibitor based triple therapy (Abstract LB-6). Hepatology 2014;60:13-4.

82. Bourliere M, Sulkowski M, Omata M, et al. An integrated safety and efficacy analysis of $>500$ patients with compensated cirrhosis treated with ledipasvir/sofosbuvir with or without ribavirin (Abstract 82). Hepatology 2014;60:239A.

83. Andreone P, Colombo MG, Enejosa JV, et al. ABT-450, ritonavir, ombitasvir, and dasabuvir achieves $97 \%$ and $100 \%$ sustained virologic response with or without ribavirin in treatmentexperienced patients with HCV genotype $1 \mathrm{~b}$ infection. Gastroenterology 2014;147:359-65, e351.

84. Forns X, Lawitz E, Zeuzem S, et al. Simeprevir with peginterferon and ribavirin leads to high rates of SVR in patients with HCV genotype 1 who relapsed after previous therapy: A phase 3 trial. Gastroenterology 2014;146:1669-79, e1663.

85. Zeuzem S, Berg T, Gane E, et al. Simeprevir increases rate of sustained virologic response among treatment-experienced patients with HCV genotype-1 infection: a phase IIb trial. Gastroenterology 2014;146:430-41, e436.

86. Lawitz E, Poordad F, Brainard DM, et al. Sofosbuvir with peginterferon-ribavirin for 12 weeks in previously treated patients with hepatitis C genotype 2 or 3 and cirrhosis. Hepatology 2014 [Epub ahead of print].

87. Gane EJ, Hyland RH, An D, et al. High efficacy of LDV/SOF regimens for 12 weeks for patients with HCV genotype 3 or 6 infection (Abstract LB-11). Hepatology 2014;60:22.

88. Gao M. Antiviral activity and resistance of HCV NS5A replication complex inhibitors. Curr Opin Virol 2013;3:514-20.

89. Moreno C, Berg T, Tanwandee T, et al. Antiviral activity of TMC435 monotherapy in patients infected with HCV genotypes 2-6: TMC435-C202, a phase IIa, open-label study. J Hepatol 2012;56:1247-53.

90. Pol S, Reddy KR, Baykal T, et al. Interferon-free regimens of ombitasvir and ABT-450/r with or without ribavirin in patients with HCV genotype 4 infection: PEARL-I study results (Abstract 1928). Hepatology 2014;60:1129A.
91. Kapoor R, Kohli A, Sidharthan S, et al. All oral treatment for genotype 4 chronic hepatitis $\mathrm{C}$ infection with sofosbuvir and ledipasvir: Interim results from the NIAID SYNERGY Trial (Abstract 240). Hepatology 2014;60:321A.

92. Esmat GE, Shiha G, Omar RF, et al. Sofosbuvir plus ribavirin in the treatment of Egyptian patients with chronic genotype $4 \mathrm{HCV}$ infection (Abstract 959). Hepatology 2014;60:662A-663A.

93. Ruane PJ, Ain D, Stryker R, et al. Sofosbuvir plus ribavirin for the treatment of chronic genotype 4 hepatitis $C$ virus infection in patients of Egyptian ancestry. J Hepatol [Epub ahead of print].

94. Kowdley KV, Lawitz E, Crespo I, et al. Sofosbuvir with pegylated interferon alfa-2a and ribavirin for treatment-naive patients with hepatitis C genotype-1 infection (ATOMIC): An open-label, randomised, multicentre phase 2 trial. Lancet 2013;381:2100-7.

95. Moreno C, Hezode C, Marcellin P, et al. Once-daily simeprevir (TMC435) with peginterferon/ribavirin in treatment-naive or treatment-experienced chronic HCV genotype 4-infected patients: Final results of a phase III trial (Abstract). J Hepatol 2014;60:S535.

96. Feld JJ. Interferon-free strategies with a nucleoside/nucleotide analogue. Semin Liver Dis 2014;34:37-46.

97. Halfon P, Sarrazin C. Future treatment of chronic hepatitis $C$ with direct acting antivirals: is resistance important? Liver Int 2012;32(Suppl 1):79-87.

98. Vermehren J, Sarrazin C. The role of resistance in HCV treatment. Best Pract Res Clin Gastroenterol 2012;26:487-503.

99. Susser S, Welsch C, Wang Y, et al. Characterization of resistance to the protease inhibitor boceprevir in hepatitis $\mathrm{C}$ virus-infected patients. Hepatology 2009;50:1709-18.

100. Svarovskaia ES, Dvory-Sobol H, Parkin N, et al. Infrequent development of resistance in genotype 1-6 hepatitis $C$ virus-infected subjects treated with sofosbuvir in phase 2 and 3 clinical trials. Clin Infect Dis 2014;59:1666-74.

101. Kohler JJ, Nettles JH, Amblard F, et al. Approaches to hepatitis C treatment and cure using NS5A inhibitors. Infect Drug Resist 2014;7:41-56. 


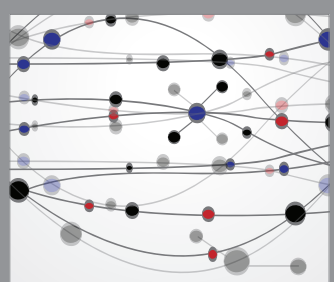

The Scientific World Journal
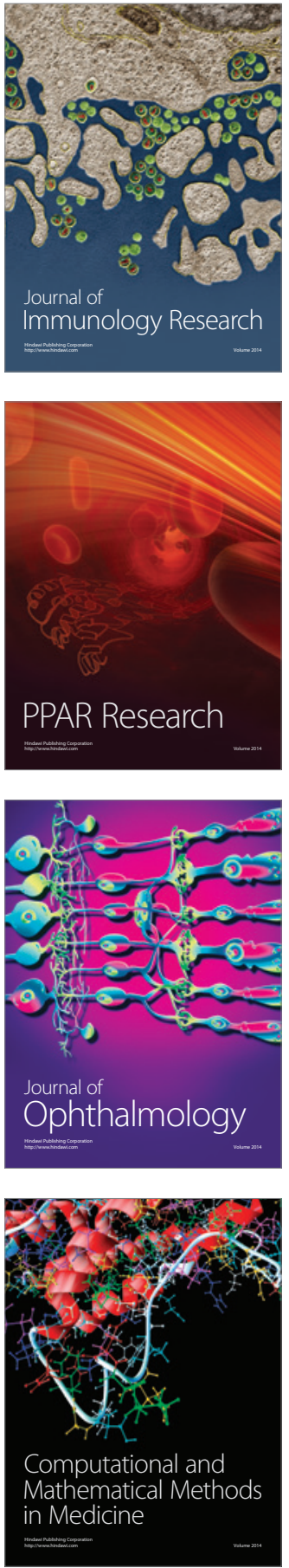

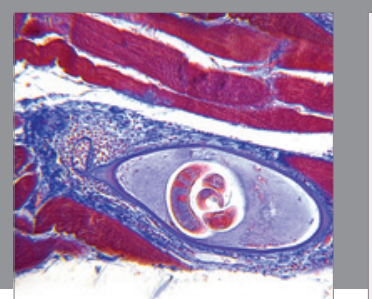

Gastroenterology Research and Practice

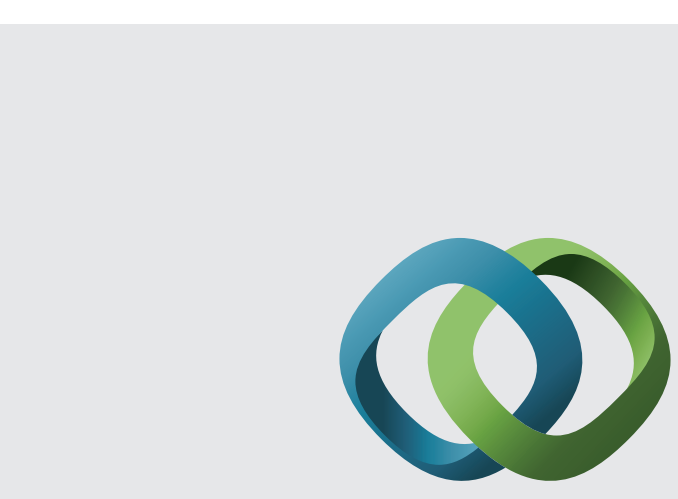

\section{Hindawi}

Submit your manuscripts at

http://www.hindawi.com
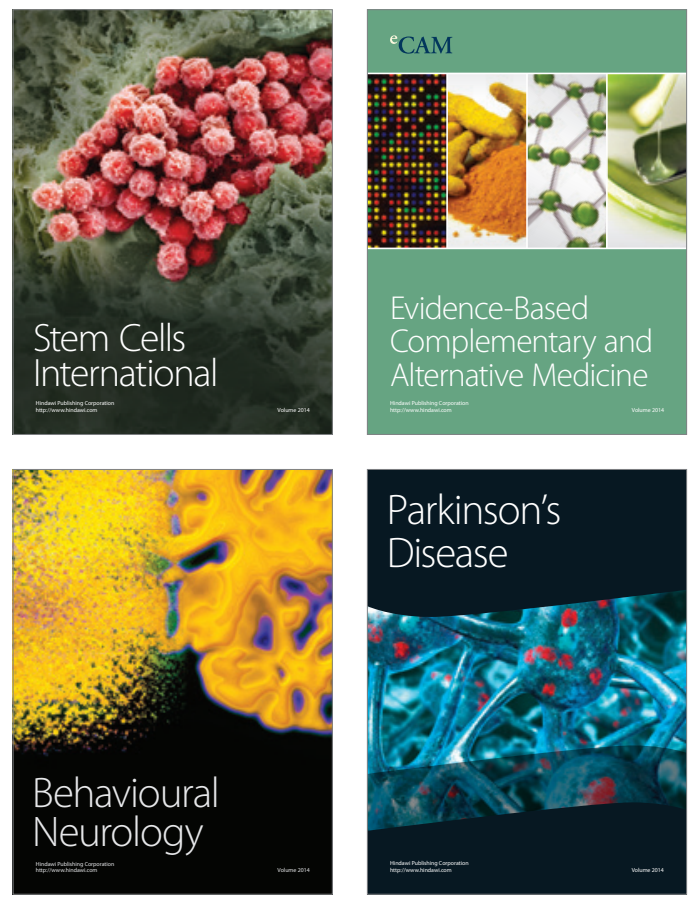
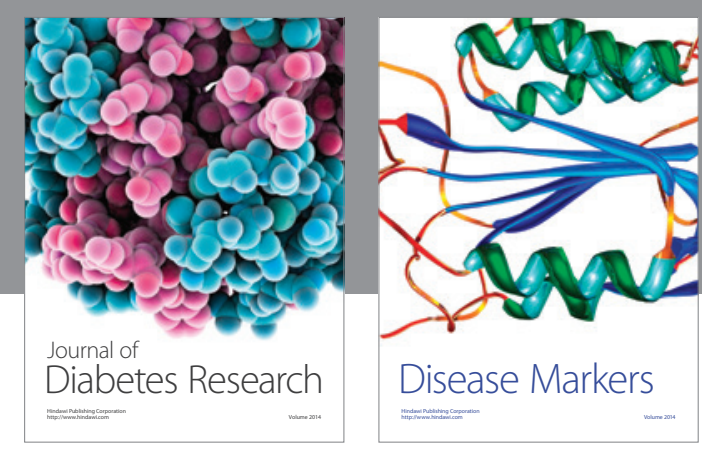

Disease Markers
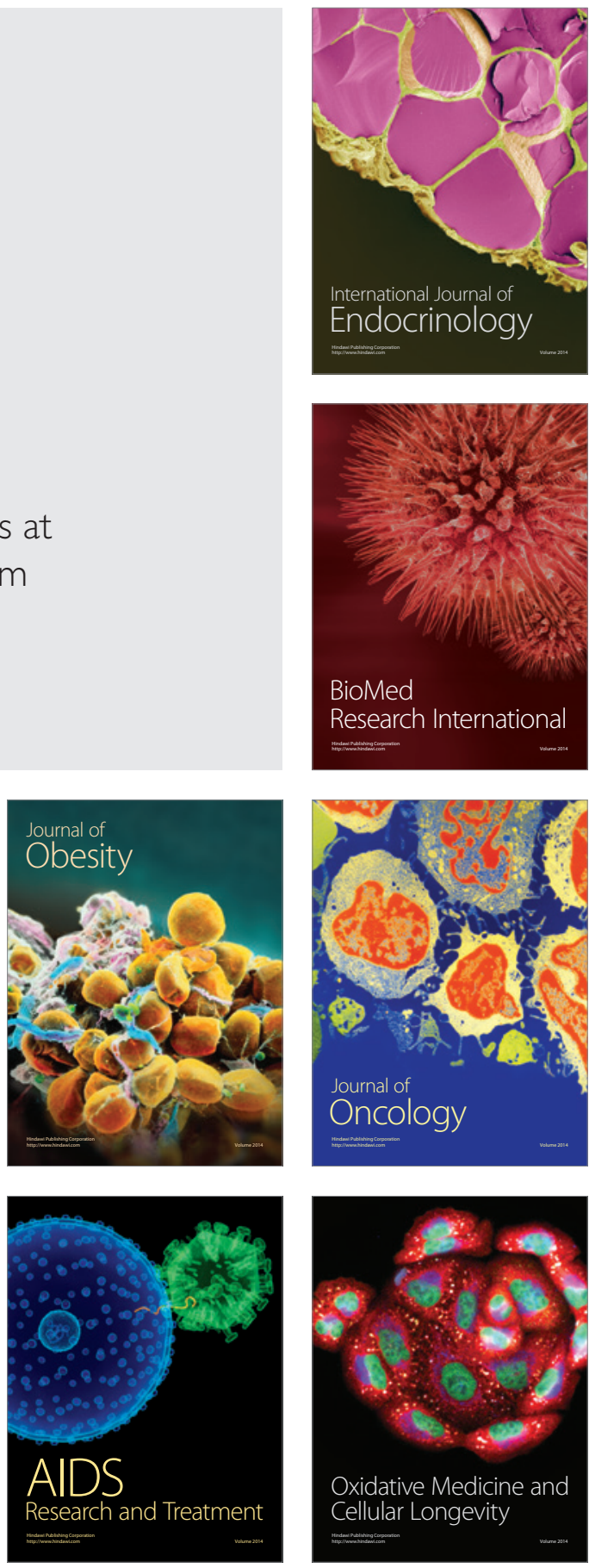